\title{
IVA y NIIF: un análisis de su relación \\ $e$ incidencia en la base gravable
}

\author{
IVA and IFRS: An Analysis of their \\ Relationship and Incidence \\ in The Taxable Base
}

\section{IVA e IFRS: uma análise do seu \\ relacionamento e incidência \\ em a base tributária}

Carlos Ariel Ossa Urrea

* Contador público, Universidad de Manizales. Especialista en Derecho tributario, Universidad Externado de Colombia. Especialista en Legislación Comercial, Universidad de Caldas. Especialista en Derecho tributario Internacional, Universidad Externado de Colombia. Candidato a magíster en Tributación, Universidad Externado de Colombia. Correo-e: carlosurrea 2007@gmail.com. oRCID ID: https://orcid.org/0000-0003-1821-6355 DoI: https://doi.org/10.18601/16926722.n17.05 


\title{
Resumen
}

En el año 2009, la IASB emitió las Normas Internacionales de Información Financiera para PYMES en procura de resolver la necesidad de tener un estándar para pequeñas y medianas empresas.

Justamente Colombia, como país miembro de la OMC y al igual que otras naciones, tomó consciencia de dichas necesidades de estandarización internacional, adoptándo las NIIF en el Derecho interno, particularmente por cuanto sus normas contables vigentes, los decretos 2649 y 2650 del año 1993, comenzaron a quedar al contener preceptos más concentrados en el aspecto transaccional y documental al servicio del Estado, que en los dueños de la inversión y los acreedores externos, en últimas, los verdaderamente interesados en la información financiera.

Sin embargo, fue solo hasta el año 2009, por medio de la Ley 1314, que se instauró la convergencia de las normas contables nacionales con las de orden internacional; esta mutación dio como consecuencia que la contabilidad ya no se basara en reglas sino en principios, lo que significó que la información financiera dejara a un lado la formalidad que determinaba el sistema tributario, por la realidad económica, cumpliendo el propósito inicial de su adopción. Son estos principios y criterios subyacentes de las normas internacionales los que constituyen el instrumento necesario e ineludible para la comprensión de las NIIF; precisamente, en el marco de dichas normas y la transformación que implican, resulta determinante la medición a valor razonable, concepto que suple la indeterminación de valor comercial como base gravable en el estatuto tributario.

Palabras clave: Base gravable; Valor razonable; Valor comercial; precio.

\begin{abstract}
In 2009, the IASB issued the International Financial Reporting Standards for SMES in an effort to resolve the need for a standard for small and medium enterprises.

Precisely Colombia, as a member country of the wTO and like other nations, became aware of these international standardization needs, adopting IFRs in domestic law, particularly as regards its current accounting standards, Decrees 2649 and 2650 of the year 1993, which at the time were a great advance, began to become obsolete due to containing more concentrated precepts in the transactional and documentary aspect at the service of the State, than in the owners of the investment and external creditors, ultimately, those truly interested in the financial information.
\end{abstract}


However, it is only until 2009, through Law 1314, that the convergence of national accounting standards with those of international order was established; This mutation resulted in accounting not being based on rules but on principles, which meant that the financial information left aside the formality that determined the tax system, for the economic reality, fulfilling the initial purpose of its adoption. It is these underlying principles and criteria of international standards that constitute the necessary and unavoidable instrument for the understanding of IFRS; precisely, within the framework of these norms and the transformation that they imply, the measurement at fair value is decisive, a concept that substitutes the indeterminacy of commercial value as a taxable base in the tax statute.

Keywords: Taxable Base; Fair Value; Commercial Value; Price.

\section{Resumo}

Em 2009, o IASB emitiu as Normas Internacionais de Relato Financeiro para PMES, em um esforço para resolver a necessidade de um padrão para pequenas e médias empresas.

Precisamente a Colômbia, como país membro da OMC e como outras nações, tomou conhecimento dessas necessidades de padronização internacional, adotando as IFRS no direito interno, particularmente no que diz respeito às suas atuais normas contábeis, os Decretos 2649 e 2650 de 1993, que na época eram um avanço, começaram a se tornar obsoletas por conterem preceitos mais concentrados no aspecto transacional e documental a serviço do Estado do que nos proprietários dos investimentos e credores externos, enfim, aqueles realmente interessados no informação financeira.

Porém, somente até 2009, através da Lei 1314, foi estabelecida a convergência das normas nacionais de contabilidade com as de ordem internacional; Essa mutação fez com que a contabilidade não se baseasse em regras, mas em princípios, o que significava que as informações financeiras anulavam a formalidade que determinava o sistema tributário, devido à realidade econômica, cumprindo o objetivo inicial de sua adoção. São esses princípios e critérios subjacentes às normas internacionais que constituem o instrumento necessário e inevitável para o entendimento das IFRS; precisamente, no marco dessas normas e da transformação que elas implicam, a mensuração ao valor justo é decisiva, conceito que substitui a indeterminação do valor comercial como base tributável no estatuto tributário.

Palavras chave: Base tributável; Valor justo; Valor comercial; Preço. 


\section{Introducción}

El estudio de la contabilidad reviste gran importancia al ser el insumo para la promulgación de informes dirigidos a usuarios, tanto internos como externos, a través de los cuales se puede determinar el estado actual y real, en términos financieros, de una persona, ya sea natural o jurídica.

Justamente, y por la trascendencia que reviste el estudio de la contabilidad, el Estado se ocupa ampliamente de su regulación, de manera que la información allí contenida presente ciertas características que la hagan comprensible y constatable para los usuarios internos y externos referidos y, particularmente, le permita la vigilancia de la correcta determinación y pago de los impuestos por parte de los ciudadanos. Es así que la información contable satisface una doble finalidad: suministrar bases de control y vigilancia al Estado y permitir intercambios comerciales transparentes y confiables.

Por supuesto, y dadas las transformaciones que el fenómeno de la globalización implica, los intereses en la claridad y eficiencia de la información contable trascienden fronteras, no siendo de exclusivo resorte de un Estado, dada la expansión de las transacciones económicas entre sujetos de distintas nacionalidades.

A pesar de la unificación del mundo de los negocios, las regulaciones estatales contables, muchas de ellas con años de antigüedad, mantenían divergencias notables que afectaban el fenómeno globalizador. A dicha situación no escapó el ordenamiento jurídico colombiano, que solo hasta el año 2009, por medio de la Ley 1314, instauró la convergencia de las normas contables nacionales con las de orden internacional fijando como objetivo que:

(...) conformen un sistema único y homogéneo de alta calidad, comprensible y de forzosa observancia, por cuya virtud los informes contables y, en particular, los estados financieros, brinden información financiera comprensible, transparente y comparable, pertinente y confiable, útil para la toma de decisiones económicas por parte del Estado, los propietarios, funcionarios y empleados de las empresas, los inversionistas actuales o potenciales y otras partes interesadas, para mejorar la productividad, la competitividad y el desarrollo armónico de la actividad empresarial de las personas naturales y jurídicas, nacionales o extranjeras (Ley 1314, 2009).

Consecuente con lo anterior, el Consejo Técnico de la Contaduría Pública (СтС), que por mandato de esta ley encontró que la mejor alternativa que interpretaba los criterios y condiciones eran las NIIF emitidas por la IASB, tomando como referente su marco conceptual, las NIIF y sus interpretaciones, las NIC y sus interpretaciones, las NIIF para pequeñas y medianas entidades (PYMES) y los fundamentos de las conclusiones emitidos por la IASB; justamente, fue a través de la Ley 1819 de 2016 que se permitió la alineación del estatuto tributario con los nuevos marcos técnicos. 
Estos nuevos marcos técnicos normativos trajeron formas distintias de medir las transacciones económicas, siendo el valor razonable una alternativa de medición basada en el precio de mercado, la cual debe tener en cuenta las características de condición, localización del activo y restricciones sobre la venta y uso del activo.

Dicho lo anterior, se expondrán las razones por las cuales la medición a Valor razonable reúne las condiciones para ser la base gravable del IVA.

\section{Conceptos y principios generales}

Los conceptos y principios generales pertenecen a la Sección 2 de las NIIF para PYMES y constituyen la herramienta metodológica que permite explicar el contenido de las normas, emitir nuevas disposiciones y enjuiciar las transacciones y eventos que han de ser reconocidos, medidos y revelados en los estados financieros (IASB, 2010). En él reposan los principios y criterios subyacentes de las normas internacionales constituyéndose en el instrumento necesario e ineludible para la comprensión de las NIIF. Allí se describen las características que debe reunir la información financiera útil, que tiene como objetivo satisfacer las necesidades de los usuarios.

Ahora bien, ¿de qué manera se consigue que la información reúna las características que permitan que sea útil? Las normas internacionales responden a este interrogante basándose en dos componentes:

- Cuándo se reconocen.

- Por cuánto se miden.

Bajo lo relatado, los criterios de reconocimiento precisan cuándo se incorporan los elementos de los estados financieros, basándose en la probabilidad de obtener flujos de efectivo. Es así como lo define el marco conceptual:

Reconocimiento es el proceso de incorporación en los estados financieros de una partida que cumple la definición de un activo, pasivo, ingreso o gasto y que satisface los siguientes criterios:

a) Es probable que cualquier beneficio económico futuro asociado con la partida llegue a, o salga de la entidad; y

b) La partida tiene un costo o valor que pueda ser medido con fiabilidad (IASB, 2009).

La medición señala las partidas que ostentan un costo o valor que puedan medirse de forma fiable, por lo que si no existe certeza que la partida puede medirse de esta manera, se descarta su reconocimiento dentro de los estados financieros (IASB, 2010). 


\section{Ilustración 1. CRiterios PARA EL RECONOCIMIENTo}

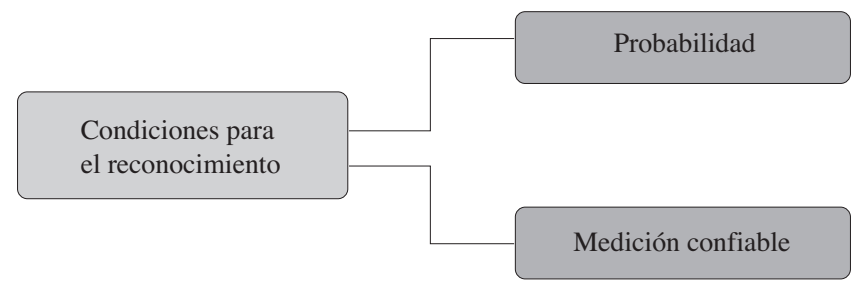

Fuente: Elaboración propia.

\section{ILUSTRACIÓN 2. BaSES DE MEDICIÓN}

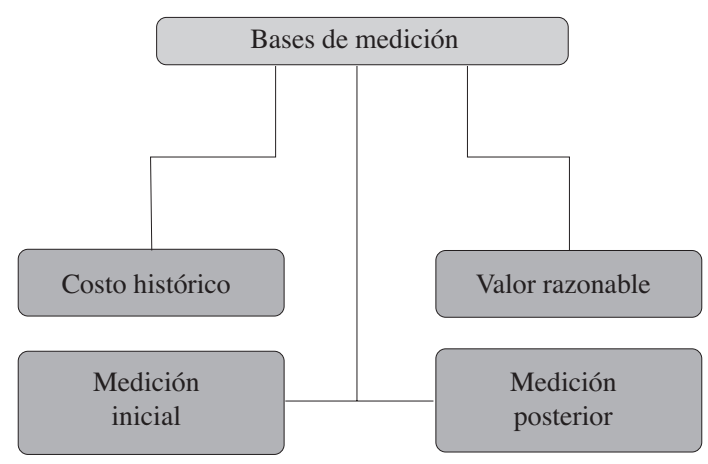

Fuente: Elaboración propia.

El estándar internacional tiene entre otras dos formas de medir los hechos económicos: el Costo histórico y el Valor Razonable (IASB, 2010).

\section{ILUSTRACIÓN 3. OPCIONES DE MEDICIÓN}

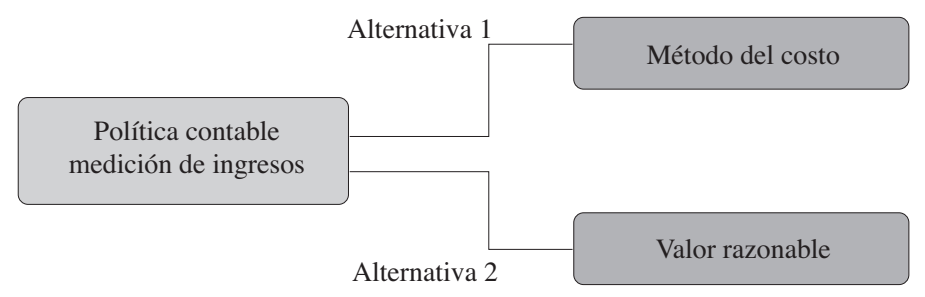

Fuente: Elaboración propia.

El Costo histórico es el importe en efectivo pagado en el momento de su adquisición cuando nos referimos a los activos; o el importe de lo recibido en efectivo cuando hacemos alusión a los pasivos (IASB, 2010). 
El valor razonable es el valor por el cual pueden ser intercambiados los activos o cancelados los pasivos entre compradores y vendedores interesados y debidamente informados en condiciones de independencia mutua (IASB, 2010).

Es importante tener claros estos dos conceptos, puesto que es el Artículo 21-1 del ET el que estableció que para la determinación del Impuesto a la Renta y Complementarios, los obligados a llevar contabilidad aplicarían estos dos sistemas: el de reconocimiento y el de medición.

Luego de superado este examen deberá estudiarse cómo medir estos elementos para lo cual se analizarán dos momentos históricos del ejercicio:

- Uno inicial, en el reconocimiento.

- Otro posterior, al cierre del ejercicio.

\section{A. Antecedentes del valor de mercado: el precio}

Han sido muchos los autores que han tratado el concepto del precio, aquí se procura destacar las teorías de algunos de ellos para poder, desde una óptica histórica, marcar las bases sobre las cuales el valor de mercado tiene su razón de ser y por qué se considera que el valor razonable tiene los fundamentos legales y conceptuales para ser base gravable del impuesto a las ventas.

Molina (2012), de la Escuela de Salamanca (1535-1601), analiza la teoría del precio justo, para lo cual presenta dos tipos de precios: el legal y el natural. El legal, según su criterio, es el definido por las autoridades bajo una ley o un decreto; el natural es el que tienen las cosas por sí mismas, que además presenta la característica de ser divisible es decir que puede variar dentro de ciertos límites, siendo la utilidad un parámetro para considerar su valor.

Otro autor, Hutchinson (1952), afirma que el precio de las cosas no se determina sobre su naturaleza sino sobre las necesidades humanas, primando la demanda que se tiene sobre el bien y su abundancia o escasez.

Bonnot de Condillac (1715-1780) expresa que la estimación o valor de un bien se hace sobre la base de su utilidad; cualidad que permite satisfacer una necesidad, no olvidando que la escasez es determinante en la estimación de valor. El valor de las cosas aumenta en la escasez y disminuye en la abundancia y muy alineado a esta teoría lo presenta Law (1966), integrando oferta, demanda, utilidad y escasez, donde manifiesta:

Los bienes derivan su valor de los usos para los cuales se pueden aplicar; y su mayor o menor valor no se deriva tanto de su mayor o menor valuación o usos necesarios, como de la mayor o menor cantidad de ellos en proporción a su demanda. Ejemplo: el agua es de gran utilidad, y sin embargo de poco valor, porque la cantidad de agua es mucho mayor que su demanda. Los diamantes son de poca utilidad, y sin embargo tienen un gran valor, porque la demanda de diamantes es mucho mayor que su cantidad. Los 
bienes de la misma especie difieren en valor por diferencias en la calidad. Por ejemplo, un caballo es mejor que otro. La cebada de un país es mejor que la de otro.

El valor de los bienes cambia ante cualquier variación en su cantidad o en la demanda de ellos o por ellos. Si la cantidad de avena es mayor que la del año anterior y la demanda es la misma o menor, el valor de la avena será menor (pp. 4-5).

Adam Smith (1723-1790) planteó la teoría del valor, diferenciando el valor de uso y el valor de cambio; el primero, por la utilidad de satisfacer una necesidad y el segundo, por la propiedad de poder ser intercambiado.

Se debe observar que la palabra valor tiene dos significados diferentes; algunas veces expresa la utilidad de un objeto en particular, y otras el poder de comprar otros bienes que la posesión de dicho bien nos permite. El primero puede llamarse valor de uso, el otro valor de cambio (Smith, 1981, p. 44).

También analizó Smith (1981) cómo la formación y fluctuación de los precios de mercado se dan por la oferta y la demanda.

$\mathrm{Al}$ detenerse en los conceptos antes expuestos, puede verse que el precio de un bien de similar naturaleza puede ser divergente, dependiendo de muchos factores y que para el presente caso de estudio la base gravable sobre la que se calcula el IVA, es relativa en cuanto:

a. El contexto geográfico donde se realiza la venta del bien o prestación del servicio, puesto que un mismo bien o servicio puede tener un precio diferente en Bogotá, en Pereira o en Manizales. Para ello se trae a colación al autor Sewall (1971), quien hace la siguiente afirmación: "El precio justo es el que se adecúa a la valuación del lugar, o sea, a lo que el objeto de una venta es comúnmente valorado en tal momento y lugar" (p. 20).

b. La Calidad de responsable de Impuesto a las Ventas de quien vende el bien o presta el servicio. Para un mismo tipo de bien no responsable de IVA podría venderlo a un menor precio al público que un responsable de IVA, puesto que el primero no puede por prescripción legal añadirle dicho impuesto al bien que está vendiendo. Aquí es importante remitirse al artículo 1.3.1.15.2 Literal a del Decreto Unificado 1625 de 2016 (Art.15 del Decreto 380 de 1996), expresando que a los no responsables de iva que vendan bienes o presten servicios, no les está permitido: "Adicionar al precio de los bienes que vendan o de los servicios que presten, suma alguna por concepto de impuesto sobre las ventas; si lo hicieren deberán cumplir íntegramente con las obligaciones de quienes pertenecen al régimen común”.

c. Tamaño de la empresa. La estructura de costos de una empresa influye en el valor bajo el cual puede ser comercializado un mismo tipo de bien. Una empresa con un tamaño 
significativo, necesariamente y bajo condiciones normales, requerirá vender a un precio más alto los bienes que una empresa con una estructura pequeña.

El tratadista William Petty (1623-1687) presenta una teoría basada en los precios de producción:

El maíz será dos veces más caro donde trabajan doscientos agricultores que hacen el mismo trabajo que podrían realizar cien: la proporción, por tanto, está compuesta con la proporción de gasto superfluo (viz, si a la causa de la carestía mencionada arriba se le agrega el doble de gastos de lo que es necesario), entonces el precio natural se cuadruplicará (Petty, 1986, p. 90).

Bajo este análisis, mal podría afirmarse que una empresa que financieramente puede dar un bien de las mismas características a un precio menor que otra que vende el mismo bien o servicio, podría estar incurriendo en contraposicion al inciso primero del artículo 463 del ET (base gravable mínima), pues su estructura comercial así se lo permite.

\section{B. Valor razonable}

El valor razonable desarrollado por la NIIF 13 fue el resultado de una extensa deliberación adelantada entre la IASB (International Accounting Standards Board) - junta de normas internacionales de Contabilidad y la FASB (Financial Accounting Standards Board) - Junta de normas de contabilidad financiera, como una necesidad de homogenizar las bases de medición, dado que dicho concepto es transversal en la mayoría de las NIIF.

\section{ILUSTRACIÓN 4. VALOR RAZONABLE}

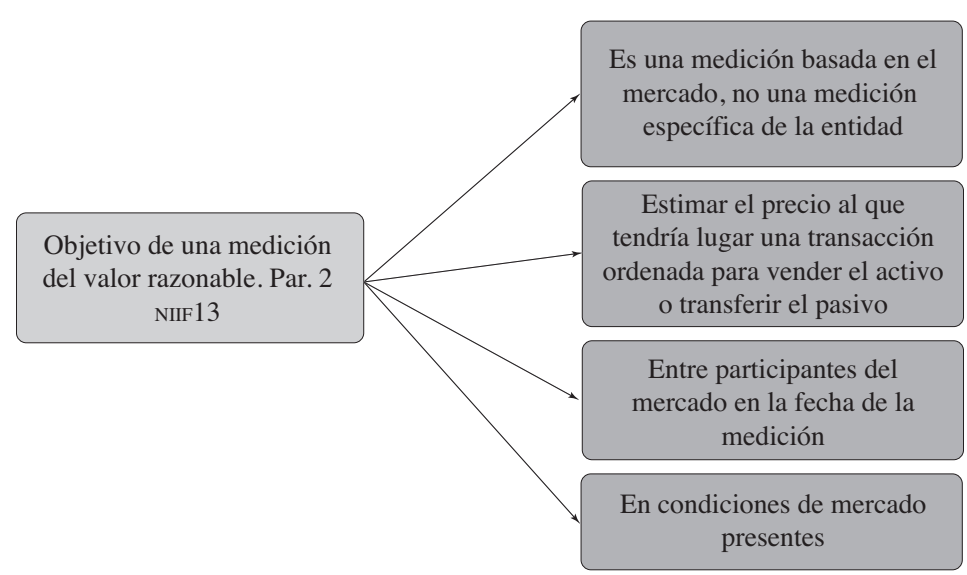

Fuente: Elaboración propia. 
Con ocasión de la crisis de los mercados financieros en los Estados Unidos durante el 2007 y 2008, muchos endilgaron la culpa de dicha crisis a la contabilidad basada en el valor razonable. Fue así como la SEC (Security and Exchange Commission) condujo el estudio sobre el valor razonable, particularmente sobre un tema denominado Mark-to Mark accounting (Valorar al mercado).

La NIIF 13 hace un desarrollo conceptual más considerable de cómo lo aborda la NIIF para pymes. En el parágrafo 9 de este estándar se encuentra la siguiente definición de valor razonable: "el precio que sería recibido por vender un activo o pagado por transferir un pasivo en una transacción ordenada entre participantes del mercado en la fecha de la medición"

El parágrafo 2 de esta NIIF describe el objetivo de una medición a valor razonable:

\section{Base gravable}

La base gravable es el valor al que se aplica la tarifa para la determinación del impuesto. El concepto unificado de IVA lo plasma de la siguiente manera: "Es el valor sobre el cual se aplica la tarifa para obtener el monto a pagar por impuesto y, de acuerdo, al artículo 338 de la Constitución Política su fijación se encuentra reservada a la ley no al reglamento" (DIAN, 2019).

En el siguiente cuadro se exponen los artículos del Estatuto Tributario que tienen mayor trascendencia en el presente estudio, por cuanto tiene elementos que impactan de manera fundamental la forma de medir los ingresos bajo norma internacional de información financiera:

ILUSTRACIÓN 5. BASE GRAVABLE EN EL IVA

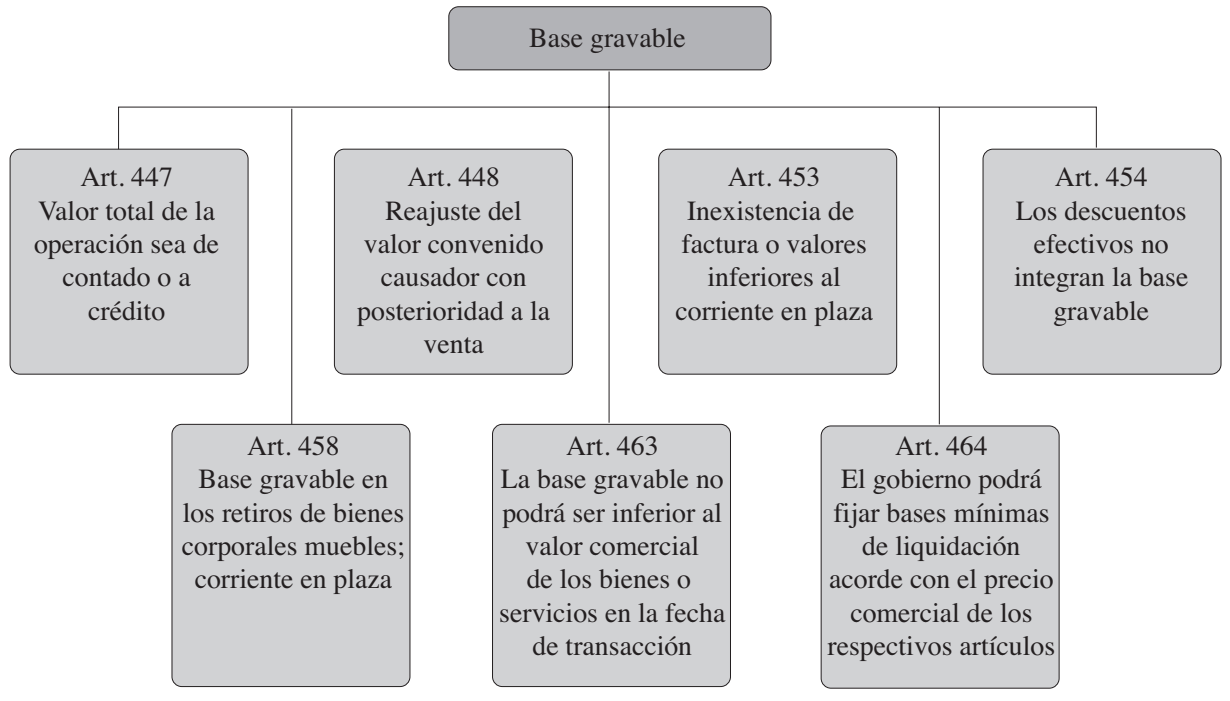

Fuente: Elaboración propia. 
De manera particular es importante retratar que el Estatuto Tributario trae un concepto que para el presente estudio resulta de la mayor importancia: Valor comercial, corriente en plaza, precio comercial. A continuación se realizará una breve referenciación de algunos de los artículos del estatuto en los cuales se presentan los referidos términos.

En el Artículo 29 del Estatuto Tributario se detalla que el valor de los ingresos en especie que sean constitutivos de ingresos, estará determinado por el valor comercial de las especies en el momento de la entrega.

Luego, el término precio comercial emerge en el artículo 90 modificado por el artículo 61 de la Ley 2010 de 2019, cuando se contempla que dicho valor sirve como determinante para obtener la renta bruta en la enajenación de activos y en el inciso tercero establece que "El precio de la enajenación es el valor comercial realizado en dinero o en especie. Para estos efectos será parte del precio el valor comercial de las especies recibidas". Y el inciso cuarto define que se entiende por valor comercial acotándolo de la siguiente forma: "Se tiene por valor comercial el señalado por las partes, el cual deberá corresponder al precio comercial promedio para bienes de la misma especie, en la fecha de su enajenación. Esta previsión también resulta aplicable a los servicios".

Posteriormente, el artículo 106 se refiere ya no a los ingresos sino a los gastos en especie, determina que el valor de los pagos o abonos en especie, que sean constitutivos de expensas necesarias o inversiones amortizables, se establecerán por el valor comercial de las especies en el momento de la entrega.

El término Valor Comercial es relevante por cuanto tiene una relación estrecha con su par en la norma internacional Valor Razonable y es la NIIF 13 la que decanta el concepto de una manera más clara: "Es el precio que se recibiría por vender un activo o que se pagaría por transferir un pasivo en una transacción ordenada entre participantes de mercado en la fecha de la medición; y refiere la misma NIIF 13 que el valor razonable es una medición basada en el mercado y no una medición específica de la entidad.

Pero veamos cómo concibe el término valor comercial su par tributario en el libro tercero del Estatuto Tributario.

El término corriente en plaza se reseña en el artículo 453 cuando se está ante la inexistencia de factura o documento equivalente o cuando las operaciones son inferiores al corriente en plaza, describiendo que el precio de la venta será el corriente en plaza.

De manera muy similar lo trae el artículo 458, modificado por el artículo 7 de la Ley 2010 de 2019, cuando considera que la base gravable de los retiros de los bienes corporales muebles e inmuebles será el valor comercial.

Igual término es utilizado en el primer inciso del artículo 463 cuando refiere que la base gravable no podrá ser inferior al valor comercial de los bienes o de los servicios, en la fecha de la transacción.

El artículo 464 del Estatuto Tributario indica que es al gobierno al que le corresponde fijar bases mínimas de liquidación de acuerdo con el precio comercial de los correspondientes artículos ante la presencia de precios inferiores vigentes en el comercio. 
ILUSTRACIÓN 6. VALOR COMERCIAL EN LA LEGISLACIÓN TRIBUTARIA Y COMERCIAL

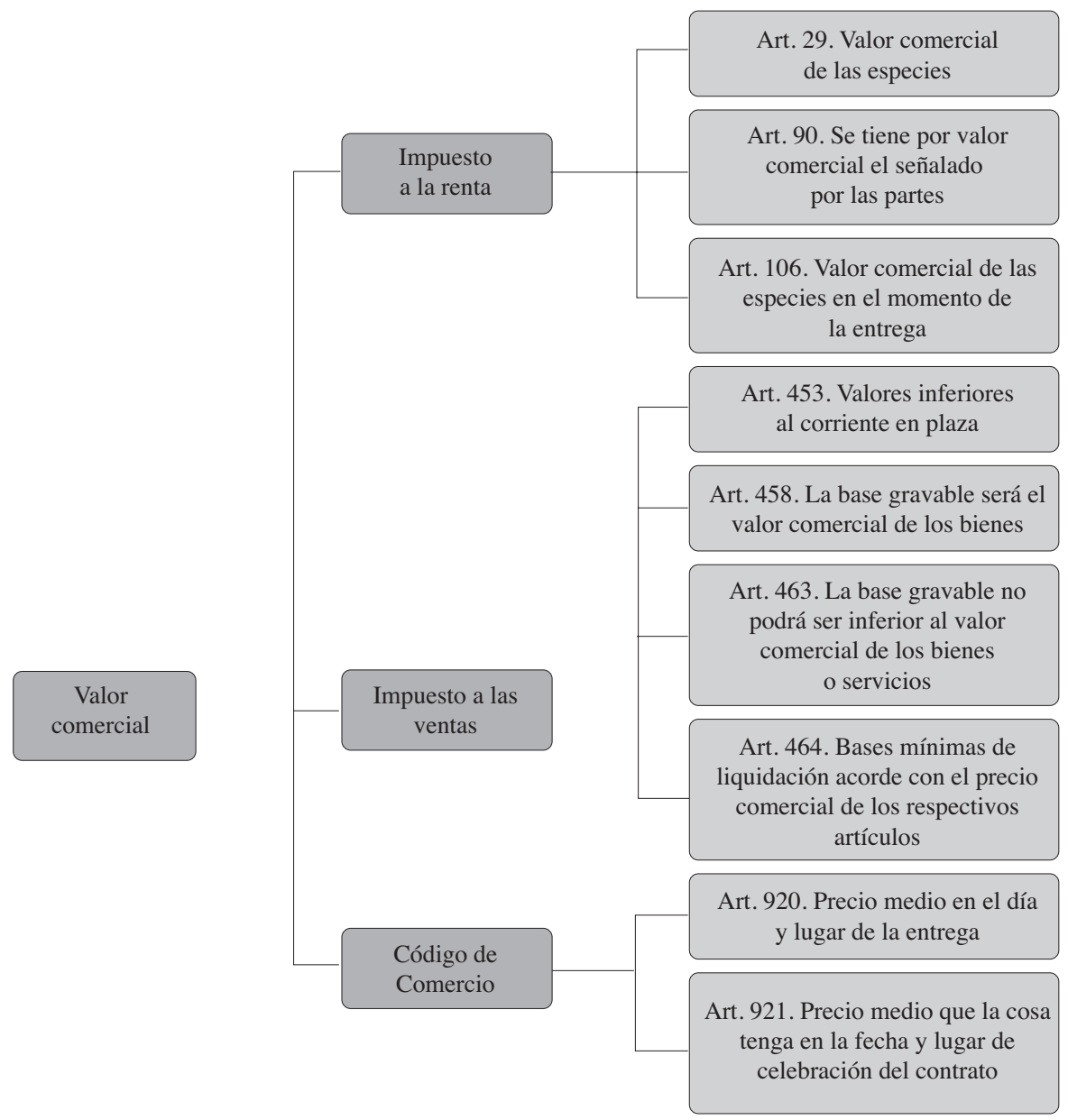

Fuente: Elaboración propia.

Por otra parte, el Código de Comercio, en su artículo 920, realiza una definición de precio en los contratos de compraventa cuando se recibe una cosa a cambio de otra, donde se presume que será el que las partes acepten en el día y lugar de la entrega. Seguidamente, el artículo 921 del mismo código permite tomar como precio el que tenga la cosa en mercados públicos tomando según dicho ordenamiento "el precio medio que la cosa tenga en la fecha y lugar de la celebración del contrato"

En Sentencia 19369 del 22 de septiembre de 2016, el Consejo de Estado definió el alcance de lo que, para efectos del IVA, se entiende por valor comercial:

[e]l precio promedio establecido en el comercio para bienes de la misma especie y calidad en la fecha de la operación, La Sala advierte que las partes coinciden en que el 
"valor comercial" de los bienes que son retirados del inventario del responsable del IVA para su uso, es el precio promedio que tienen los equipos de cómputo y de comunicaciones en el mercado, en la fecha y lugar en que se realiza la operación.

En esta sentencia deben destacarse 2 condiciones importantes de la definición de Valor comercial:

- Precio promedio establecido en el comercio para los bienes de la misma especie.

- Fecha y lugar de la operación.

A su vez, la sentencia enfatizó en la indeterminación del artículo 458 del Estatuto Tributario en el concepto del Valor comercial:

En esas condiciones, la Sala considera que la demandante demostró con razones suficientes el vacío jurídico que contiene el artículo 458 del ET, al momento de referirse al "valor comercial" de los bienes para el cálculo del IVA, lo que daba lugar a interpretar de diversas manera el alcance de ese concepto.

Finalmente, la sala dejó por sentada la igualdad que se presenta en el Estatuto Tributario y en el Código de Comercio en la definición del término valor comercial:

En esa medida, la Sala considera que la definición de "valor comercial" que contiene el estatuto tributario no es sustancialmente diferente de la que desarrolla el Código de Comercio. Esto, por cuanto dichos artículos parten de la base de que por "valor comercial" se entiende como aquel precio o valor que tienen los bienes de la misma especie y condiciones en el mercado para la fecha y lugar de la operación.

Para la sala resulta inequívoco que la definición de Valor comercial del estatuto no dista de la definida en el Código de Comercio, pues ambas definiciones tienen algo en común: bienes de la misma especie, condiciones en el mercado, fecha y lugar de La operación.

En este orden de ideas, para la sala le asiste la razón a la DIAN, al argumentar que el valor comercial era el precio con el que usualmente la sociedad demandante le vendía a sus clientes (precio de salida, término usado en NIIF) y no el precio por el cual adquiría los bienes a los proveedores (Precio de entrada término usado en NIIF)

En el parágrafo 24 de la NIIF 13 se define uno de los elementos del valor razonable: el precio. Como se puede evidenciar, el precio tiene elementos comunes que ha adoptado nuestra legislación y que nos permitirá equiparar la manera como lo aborda la norma internacional en consonancia con el Estatuto Tributario y el Código de Comercio.

En siguiente cuadro se realiza una desagregación de los conceptos que trae la definición. 


\section{ILUSTRACIÓN 7. El PRECIO}

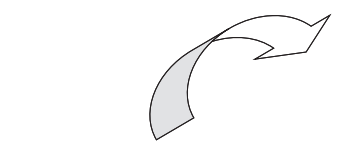

En condiciones de mercado presentes (es decir, un precio de salida)

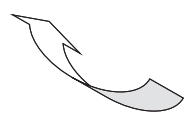

El valor razonable es el precio que se recibiría por la venta de un activo o se pagaría por la transferencia de un pasivo

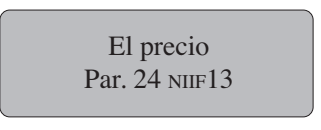

En la fecha de la medición

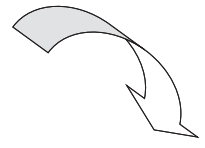

En una trasacción ordenada en el mercado principal (o más ventajoso)

Fuente: Elaboración propia.

Para la medición de valor razonable de los activos no financieros, es decir, aquellos que tienen vocación de permanencia dentro de las compañías, se tendrá en cuenta la capacidad que tiene dicho activo en generar beneficios económicos, ya sea mediante su utilización o a través de su venta. También se deberá considerar si el activo de manera individual genera beneficios o si hace parte de un grupo de activos que generan beneficios en conjunto (IASB, 2010).

Para este último caso se partirá de la participación que tendrá en la generación de beneficios de dicho grupo de activos. El máximo y mejor uso deberá considerar los siguientes criterios:

\section{Ilustración 8. CRITERIos del MáXimo y MEJor uso}

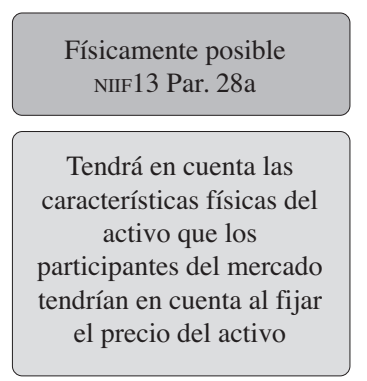

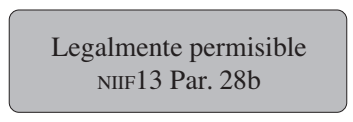

Las restricciones legales de utilización del activo que los participantes del mercado tendrían en cuenta al fijar el precio del activo
Financieramente factible NIIF23 Par. 28c

Produzca una rentabilidad de la inversión que los participantes del mercado requieren del activo destinado a un uso determinado

Fuente: Elaboración propia.

Para un mayor entendimiento de esta definición debemos remitirnos a los parágrafos 57 a 60 de esta NIIF que nos aclara cuál es el precio que se debe tomar en determinada transacción como Valor razonable. El parágrafo 57 aborda el reconocimiento inicial, y explica que existen dos tipos de precios: un precio de entrada, que es el pagado por adquirir el 
activo o asumir un pasivo, y un precio de salida que es al que nos remite la definición; el precio que se recibiría por vender el activo o pagaría por transferir el pasivo, es decir, yo podría comprar un activo a un valor por debajo del mercado pero dicha transacción puede diferir del valor razonable de dicho activo, lo que conllevaría reconocer una ganancia o una pérdida por parte de la entidad. En conclusión, el Valor Razonable es el precio de Salida.

Ahora bien, en lo que corresponde al valor de mercado, como ya se ha analizado, depende de lo que determinen la oferta y la demanda en una fecha establecida, el cual, según la NIIF 13 en su parágrafo 62, se fija a partir de unas técnicas de valoración que tendría una transacción ordenada de venta del activo entre participantes en la fecha de la medición en las condiciones de mercado presentes. Estas tres técnicas son:

\section{EL ENFOQUE DE MERCADO}

"Una técnica de valoración que utiliza los precios y otra información relevante generada por transacciones de mercado que involucran activos, pasivos o un grupo de activos y pasivos idénticos o comparables (es decir, similares), tales como un negocio" (Apéndice a NIIF 13). Esta técnica utiliza información generada por transacciones del mercado, como la utilización de múltiplo o matrices de fijación de precios.

\section{EL ENFOQUE DEL COSTO}

"Una técnica de valoración que refleja el importe que se requeriría en el momento presente para sustituir la capacidad de servicio de un activo (a menudo conocido como costo de reposición corriente)" (Apéndice a NIIF 13).

\section{EL ENFOQUE DEL INGRESO}

"Las técnicas de valoración que convierten importes futuros (por ejemplo, flujos de efectivo o ingresos y gastos) en un importe presente único (es decir, descontado). La medición del valor razonable se determina sobre la base del valor indicado por las expectativas de mercado presentes sobre esos importes futuros" (Apéndice a NIIF 13).

Sea cual fuere la técnica que se escogiese, esta debería aplicarse de manera consistente; no obstante, se podría cambiar cuando de una nueva técnica pudiese obtenerse una medición de valor razonable más representativa. Este cambio de medición se contabilizará como un cambio en una estimación contable.

Aunado a lo anterior para la estimación del valor razonable tanto en NIIF para PYMES como en NIIF plenas, existe una jerarquía para su determinación, la cual se clasifica en tres tipos de niveles a saber: 
Datos de entrada de Nivel 1: "son precios cotizados (sin ajustar) en mercados activos para activos o pasivos idénticos a los que la entidad puede acceder en la fecha de la medición" (Parágrafo 76 NIIF 13).

Datos de entrada de Nivel 2: corresponde a aquellos precios distintos de los precios cotizados pero que son observables, podrían ser datos extraídos de una transacción en un mercado similar para una transacción reciente para ese tipo de bien o servicio (IASB, 2010).

Datos de entrada de Nivel 3: "Los datos de entrada de Nivel 3 son datos de entrada no observables para el activo o pasivo" (Parágrafo 86 NIIF 13). Para ello utilizaría la mejor información disponible que podrían ser datos de la propia entidad.

Cuando se utiliza una técnica de medición mediante la cual la información más relevante se obtiene de la observación del mercado, dicha medición se clasificará en nivel 2; por el contrario, si la medición se obtiene de variables no observables del mercado, la medición se clasificara en el nivel 3.

\section{Valor comercial según el Estatuto Tributario}

En el estatuto Tributario se encuentra el término Valor Comercial, no haciendo una denotación clara de su significado para fines impositivos; para el caso que nos ocupa, solo haremos referencia a dicho término en los artículos que se reseñan la determinación de los ingresos.

TABLA 1. VALOR COMERCIAL EN EL RÉGIMEN DE IMPUESTO A LA RENTA

\begin{tabular}{|l|l|}
\hline Artículo 29 del ET & $\begin{array}{l}\text { Estipula que el valor de los ingresos en especie se determina por el valor comercial de las } \\
\text { especies en el momento de la entrega. }\end{array}$ \\
\hline $\begin{array}{l}\text { Artículo 90 ET modifica- } \\
\text { do por el artículo 53 de la } \\
\text { Ley } 1943 \text { de } 2018\end{array}$ & $\begin{array}{l}\text { Señala que la renta bruta o la pérdida proveniente de la enajenación de activos está cons- } \\
\text { tituido por el precio de enajenación menos el costo del activo. Además establece que el } \\
\text { valor comercial es el determinado por las partes, el cual deberá corresponder al precio } \\
\text { comercial promedio para bienes de la misma especie en la fecha de enajenación, haciendo } \\
\text { esta misma estimación para los servicios. }\end{array}$ \\
\hline $\begin{array}{l}\text { Artículo 90-3 ET Adicio- } \\
\text { nado por el artículo 54 de } \\
\text { la Ley 1943 de 2018 }\end{array}$ & $\begin{array}{l}\text { Cuando a ventas indirectas se refiere de acciones en sociedades, derechos o activos ubi- } \\
\text { cados en territorio nacional, el activo subyacente producto de esa venta deberá corres- } \\
\text { ponder a su valor comercial. }\end{array}$ \\
\hline Artículo 304 ET & $\begin{array}{l}\text { Determina que las ganancias ocasionales provenientes de loterías, premios, rifas, apues- } \\
\text { tas y similares cuando estas se otorguen en dinero, su cuantía se fija por lo efectivamente } \\
\text { recibido pero cuando sean percibidas en especie se tomarán por el valor comercial del } \\
\text { bien al momento de recibirse. }\end{array}$ \\
\hline Art 106 ET & $\begin{array}{l}\text { El valor de los pagos en especie se determina por el valor comercial en el momento de } \\
\text { la entrega. }\end{array}$ \\
\hline
\end{tabular}

Fuente: Elaboración propia.

Los anteriores artículos en cuanto a renta se refieren. En cuanto a IVA se encuentran en las disposiciones contenidas en la Tabla 2. 
Tabla 2. Valor Comercial en el régimen de Impuesto a las Ventas

\begin{tabular}{|l|l|}
\hline $\begin{array}{l}\text { Artículo } 458 \text { modificado } \\
\text { por la Ley } 1943 \text { de } 2018\end{array}$ & $\begin{array}{l}\text { Estipula que la base gravable en los retiros de bienes corporales muebles e inmuebles, } \\
\text { en lo que se refiere al literal b) del artículo 421, se establecerá por el valor comercial de } \\
\text { los bienes. }\end{array}$ \\
\hline Artículo 463 del ET & $\begin{array}{l}\text { La base gravable mínima enunciada en él plantea que, en ningún caso, la base gravable } \\
\text { podrá ser inferior al valor comercial de los bienes o de los servicios, en la fecha en que } \\
\text { se transen. }\end{array}$ \\
\hline Artículo 464 ET & $\begin{array}{l}\text { Por último, el presente artículo dispone que a fin de evitar que se declaren opera- } \\
\text { ciones por precios notoriamente inferiores a los vigentes en el comercio, el Gobierno } \\
\text { Nacional podrá fijar bases mínimas de liquidación acordes con el precio comercial de los } \\
\text { respectivos artículos. }\end{array}$ \\
\hline
\end{tabular}

Fuente: Elaboración propia.

Todos los anteriores hacen referencia expresa al valor comercial pero ni el Estatuto Tributario ni sus reglamentos aluden a tal, es la jurisprudencia la que ha definido dicho término, pero no se ha planteado la forma en que dicho valor se determinará.

\section{E. Valor razonable vs. Valor de mercado}

De cara a lo anterior, la forma como define la norma internacional el valor razonable tiene una gran similitud con la definición de valor comercial del Código de Comercio y la interpretación jurisprudencial del Consejo de Estado, lo que lleva a concluir que dicho concepto (Valor comercial) guarda las mismas características en las tres normas. La tabla 3 permite visualizar mejor su similitud.

Es de reiterar que el valor razonable se puede aplicar tanto en la medición inicial como en la medición posterior, es decir, esta medición se podrá utilizar tanto en el momento cuando nace el hecho económico, como posteriormente en el corte del ejercicio (Parágrafo 8 de la NIIF 13).

Todo lo anterior a fin de afirmar que la base gravable puede tener innumerables formas de medición y no con ello se está violentando uno de los elementos esenciales del tributo.

A raíz de lo anteriormente expuesto, y a manera de conclusión, puede afirmarse que el valor razonable de la norma internacional y el valor comercial que define, tanto el Código de Comercio como el Estatuto Tributario, son en esencia el mismo concepto.

A partir de ello, resulta propio referirse nuevamente a la forma como la norma internacional, tanto en las NIIF plenas como en las NIIF para PYMES, determina su medición inicial.

El parágrafo 9 de la NIIF 18 en plenas define: "Los ingresos de actividades ordinarias se medirán al valor razonable de la contraprestación recibida o por recibir".

Entre tanto, el parágrafo 23.3 de las NIIF para PYMES puntualiza: "Una entidad medirá los ingresos de actividades ordinarias al valor razonable de la contraprestación recibida o por recibir. El valor razonable de la contraprestación, recibida o por recibir, tiene en cuenta el importe de cualesquiera descuentos comerciales, descuentos por pronto pago y rebajas por volumen de ventas que sean practicados por la entidad". 
Tabla 3. Comparativo legal de Valor comercial

\begin{tabular}{|c|c|c|}
\hline NIIF plenas & Código de Comercio & Estatuto Tributario \\
\hline Valor razonable NIIF 13 & El precio & Valor comercial \\
\hline $\begin{array}{l}\text { Parágrafo } 9 \text {. Esta NIIF define valor } \\
\text { razonable como el precio que sería } \\
\text { recibido por vender un activo o pa- } \\
\text { gado por transferir un pasivo en una } \\
\text { transacción ordenada entre partici- } \\
\text { pantes del mercado en la fecha de la } \\
\text { medición. }\end{array}$ & $\begin{array}{l}\text { Artículo } 920 \text {. No habrá compraventa } \\
\text { si los contratantes no convienen en el } \\
\text { precio o en la manera de determinarlo. } \\
\text { Pero si el comprador recibe la cosa, } \\
\text { se presumirá que las partes aceptan } \\
\text { el precio medio que tenga en el día y } \\
\text { lugar de la entrega. }\end{array}$ & $\begin{array}{l}\text { Artículo } 90 \text {. Inciso. } 3 \text {. El precio de } \\
\text { la enajenación es el valor comercial } \\
\text { realizado en dinero o en especie. Pa- } \\
\text { ra estos efectos será parte del pre- } \\
\text { cio el valor comercial de las especies } \\
\text { recibidas. }\end{array}$ \\
\hline El precio & $\begin{array}{c}\text { Precio determinable por el } \\
\text { promedio del mercado }\end{array}$ & $\begin{array}{c}\text { Base gravable en los retiros de } \\
\text { bienes corporales muebles }\end{array}$ \\
\hline $\begin{array}{l}\text { Parágrafo } 24 \text {. El valor razonable es el } \\
\text { precio que se recibiría por la venta de } \\
\text { un activo o se pagaría por la transfe- } \\
\text { rencia de un pasivo en una transacción } \\
\text { ordenada en el mercado principal (o } \\
\text { más ventajoso) en la fecha de la me- } \\
\text { dición en condiciones de mercado } \\
\text { presentes (es decir, un precio de sa- } \\
\text { lida) independientemente de si ese } \\
\text { precio es observable directamente o } \\
\text { estimado utilizando otra técnica de } \\
\text { valoración. }\end{array}$ & $\begin{array}{l}\text { Artículo 921. Cuando las partes pa- } \\
\text { ra la determinación del precio se re- } \\
\text { mitan al que tenga la cosa en ferias, } \\
\text { mercados públicos de valores y otros } \\
\text { establecimientos análogos, o estipulen } \\
\text { como precio el corriente de plaza, se } \\
\text { tomará el precio medio que la cosa } \\
\text { tenga en la fecha y lugar de la cele- } \\
\text { bración del contrato }\end{array}$ & $\begin{array}{l}\text { Artículo 458. [Modificado. Ley } \\
\text { 1943/2018, art 7]. En los retiros a que } \\
\text { se refiere el literal b) del artículo 421, } \\
\text { la base gravable será el valor comer- } \\
\text { cial de los bienes. }\end{array}$ \\
\hline $\begin{array}{c}\text { Bases de Medición NIIF para PYMES. } \\
\text { Sección } 2\end{array}$ & & Base Gravable Mínima \\
\hline \multirow[t]{3}{*}{$\begin{array}{l}\text { Parágrafo } 2.34 \text { (b) Valor razonable es } \\
\text { el importe por el cual puede ser inter- } \\
\text { cambiado un activo, o cancelado un } \\
\text { pasivo, entre un comprador y un ven- } \\
\text { dedor interesado y debidamente infor- } \\
\text { mado, que realizan una transacción en } \\
\text { condiciones de independencia mutua. }\end{array}$} & & $\begin{array}{l}\text { Artículo } 463 \text {. [Creado por Art. } 11 \text { del } \\
\text { D.E. } 3541 \text { de 1983]. En ningún ca- } \\
\text { so la base gravable podrá ser infe- } \\
\text { rior al valor comercial de los bienes } \\
\text { o de los servicios, en la fecha de la } \\
\text { transacción. }\end{array}$ \\
\hline & & $\begin{array}{c}\text { El gobierno puede fijar bases } \\
\text { mínimas de liquidación }\end{array}$ \\
\hline & & $\begin{array}{l}\text { Artículo 464. [Creado por el Art. } 18 \\
\text { del D.L. } 2368 \text { de 1974] Con el fin de } \\
\text { evitar que se declaren operaciones por } \\
\text { precios notoriamente inferiores a los } \\
\text { vigentes en el comercio, el Gobierno } \\
\text { Nacional podrá fijar bases mínimas } \\
\text { de liquidación acordes con el precio } \\
\text { comercial de los respectivos artículos. }\end{array}$ \\
\hline
\end{tabular}

Fuente: Elaboración propia.

Ambos estándares refieren el valor razonable como la base de medición, lo que determina de manera imperiosa acudir a este concepto para establecer los importes monetarios sobre los cuales se deberá calcular el IVA. 


\section{F. Reconocimiento y medición con la Ley 1819 de 2016}

Realizado el análisis conceptual de cómo concibe la norma internacional la determinación del precio al momento de realizar una operación de venta de bienes, no se puede dejar de lado lo instituido por la Ley 1819 de 2016 en cuanto dejó muchos vacíos en la forma como se reconocen y se miden los hechos económicos.

Así puede contrastarse en el adicionado Articulo 21-1 del Estatuto Tributario, sobre la convergencia entre la norma tributaria y la Norma Internacional de Información Financiera, en el que solo se hace alusión en la determinación del Impuesto a la Renta y Complementarios y solo para aquellas personas naturales o jurídicas que estén obligadas a llevar contabilidad o que de manera voluntaria decidan aplicarla, dejando claro de manera expresa que la ley tributaria podría disponer de un tratamiento diferente respetando la independencia y autonomía de las normas contables y tributarias según lo preceptuado en el artículo 4 de la Ley 1314 de 2009.

Este adicionado artículo 21-1 del Estatuto Tributario terminó refrendando en su parágrafo 6 que para efectos fiscales las mediciones a valor presente o a valor razonable deberán reconocerse al costo, precio de adquisición o valor nominal y las diferencias que se llegasen a presentar no tendrían efecto en el Impuesto a la Renta y Complementarios, por lo que el problema que surgiría es si habría efectos en la determinación en el impuesto sobre las ventas.

Partiendo de los conceptos definidos en el capítulo primero, a continuación se pretende realizar con el siguiente esquema un símil conceptual entre el reconocimiento y medición de la norma Internacional y la valoración que de la Base gravable trae el régimen de Impuesto a las ventas e identificar los puntos de convergencia y los que se contraponen.

\section{G. Devengo vs. causación}

Para comprender este comparativo debe entenderse lo que es el devengo en la norma internacional. El parágrafo 2.36 de las NIIF para PYMEs lo define así: "Una entidad elaborará sus estados financieros, excepto en lo relacionado con la información sobre flujos de efectivo, utilizando la base contable de acumulación (o devengo). De acuerdo con la base contable de acumulación (o devengo), las partidas se reconocerán como activos, pasivos, patrimonio, ingresos o gastos cuando satisfagan las definiciones y los criterios de reconocimiento para esas partidas". Es decir, el devengo es el momento en el cual se reconoce un elemento de los estados financieros independiente de que su pago se haya o no realizado.

El artículo 429 del Estatuto Tributario determinó los momentos en que se tiene causado el impuesto y los condicionó a dos situaciones: En las ventas, en la fecha de emisión de la factura o documento equivalente, y a falta de esto en la entrega así haya de por medio un pacto de reserva de dominio, pacto de retroventa o condición resolutoria. La norma internacional solo tiene en cuenta el momento de la entrega física entendida como la asunción 
de los riesgos y beneficios al comprador, pues la emisión de la factura no determina un hecho económico que dé lugar a reconocimiento (IASB, 2010).

La entrega de la factura se vuelve un requisito formal carente de valuación económica si no se ha realizado el traslado de riesgos y beneficios y es el refrendado artículo 28 del estatuto que reafirma que los ingresos para los obligados a llevar contabilidad serán los devengados contablemente, dándole relevancia a la realidad económica de la transacción por encima de la formalidad.

Ahora bien, el nuevo artículo 21-1 del Estatuto Tributario en su parágrafo 3 lo sintetizó de la siguiente manera: "Para los fines de este Estatuto, cuando se haga referencia al término de causación, debe asimilarse al término y definición de devengo o acumulación de que trata este artículo".

La norma fiscal convalida el concepto de devengo con la causación dándoles plena equivalencia, lo que de suyo denota que, en este punto, no se presentan diferencias. Es importante anotar que el libro tercero de Impuesto a las Ventas no insinuó cambios en cuanto a los sistemas de reconocimiento y medición, pues solo hizo énfasis en el Impuesto a la Renta y Complementarios y sometiendo a esta regla a las personas naturales que opten por llevar contabilidad.

De acuerdo con lo ya conceptuado, hay una paridad en los conceptos de reconocimiento de la norma internacional y la causación de la norma fiscal. En el presente cuadro lo podemos visualizar de mejor manera.

Tabla 4. Devengo vs. Causación

\begin{tabular}{|c|c|c|c|c|}
\hline \multicolumn{3}{|c|}{$\begin{array}{l}\text { NIFF para PYMES } \\
\text { Sección } 2\end{array}$} & $\begin{array}{c}\text { Impuesto a la Renta } \\
\text { Libro Primero }\end{array}$ & \\
\hline \multirow{3}{*}{ 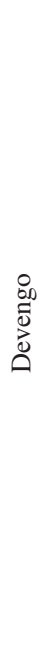 } & \multirow[t]{3}{*}{$\begin{array}{l}\text { Base contable de acumulación } \\
\text { o devengo }\end{array}$} & \multirow[t]{3}{*}{$\begin{array}{l}\text { De acuerdo con la base de acu- } \\
\text { mulación o devengo, las partidas } \\
\text { se reconocerán como activos, } \\
\text { pasivos, patrimonio, ingresos o } \\
\text { gastos cuando satisfaga las defi- } \\
\text { niciones y los criterios de recono- } \\
\text { cimiento para esas partidas. } 2.36\end{array}$} & $\begin{array}{l}\text { Ley } 1819 \text { art } 21 \text {-1 Parágrafo } 3 . \\
\text { Para los fines de este Estatuto, } \\
\text { cuando se haga referencia al tér- } \\
\text { mino de causación, debe asimi- } \\
\text { larse al término y definición de } \\
\text { devengo o acumulación de que } \\
\text { trata este artículo. }\end{array}$ & \\
\hline & & & $\begin{array}{l}\text { Impuesto a las Ventas } \\
\text { Libro Tercero }\end{array}$ & \\
\hline & & & $\begin{array}{l}\text { Artículo 429. Momento de causa- } \\
\text { ción. El impuesto se causa: } \\
\text { a) En las ventas, en la fecha de } \\
\text { emisión de la factura o documen- } \\
\text { to equivalente y a falta de estos, } \\
\text { en el momento de la entrega, aun- } \\
\text { que se haya pactado reserva de } \\
\text { dominio, pacto de retroventa o } \\
\text { condición resolutoria. }\end{array}$ & \\
\hline
\end{tabular}

Fuente: Elaboración propia. 


\section{H. Medición en NIF vs. base gravable en IVA}

El parágrafo 23.3 de las NIIF para PYMES señala que los ingresos de actividades ordinarias se medirán al valor razonable de la contraprestación recibida o por recibir y, de manera muy similar aunque con más amplitud conceptual, lo define el párrafo 10 de las NIIF 13, el cual anota que los ingresos de actividades ordinarias producto de una transacción se determinarán por el acuerdo entre la entidad y el vendedor midiéndose al valor razonable de la contrapartida, recibida o por recibir, revistiendo en la mayoría de los casos la forma de efectivo o equivalentes al efectivo recibidos o por recibir. También se reitera en el párrafo 11 que el valor razonable pudiera ser menor que la cantidad nominal de efectivo cobrada o por cobrar.

Ahora bien, la base gravable, tal como ha sido concebida por el artículo 447 del Estatuto Tributario, incluye el total de la operación sea esta de contado o a crédito incluyendo los gastos de financiación, sean estos corrientes o moratorios, y todas las demás erogaciones que aunque hayan sido percibidas por separado estuviesen sometidas a imposición.

Aquí la norma internacional concibe de una manera diferente el precio del bien sujeto a su comercialización y refrendando lo que se dijo en renglones anteriores, se hace una separación entre lo que es el valor comercial y lo que corresponde a su financiación. (IASB, 2010). Para las NIIF solo existe un valor transaccional en la medición inicial, y es el valor por el cual estaría dispuesto a intercambiar un bien en el momento actual con plena libertad e información (Valor Razonable) (IASB, 2010), es decir, cualquier valor que se aparte de esta base deberá ser reconocido como intereses, obviamente sujeto a Impuesto a las ventas, no cabe la menor duda, pero dicho valor se someterá a un diferimiento del cual se hablará más adelante.

En la tabla 5 se hace un símil entre la base gravable retomando solo lo concebido por la Ley 1819 sin tomar, de momento, los artículos 447 y siguientes del estatuto, haciéndose énfasis en la nueva regulación NIIF como la ha concebido el estatuto y comparándola con la medición tanto inicial como posterior en lo que la norma llama instrumentos financieros básicos y dentro de los cuales están las facturas de venta a crédito.

\section{Medición de los ingresos con descuentos financieros}

Una de las novedades que trajo consigo la normatividad internacional concierne a los descuentos comerciales que se sustraerán desde el reconocimiento inicial cuando se tiene una certeza razonable de que dicho descuento será otorgado partiendo de la habitualidad de los pagos que históricamente han venido realizando los clientes.

Es decir, mientras que bajo la norma fiscal solo se pueden descontar para la determinación de la base gravable los descuentos comerciales, la norma internacional fuerza a que la venta se reconozca por el importe neto de cualquier descuento, sea comercial o financiero, y que implicará un recaudo mucho menor en el IVA si se tomara dicho valor como su base imponible. 
Tabla 5. Medición vs. Base Gravable

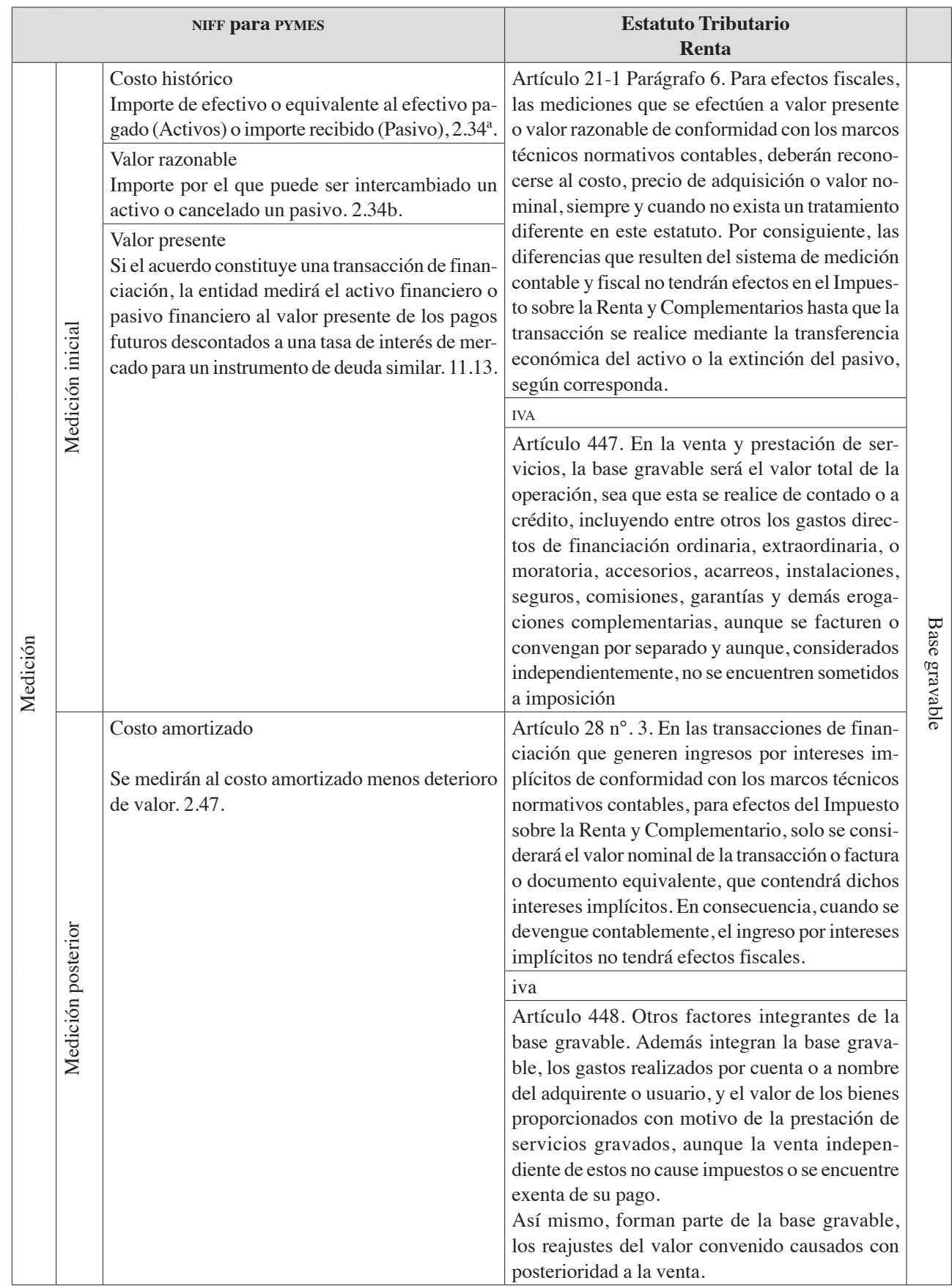

Fuente: Elaboración propia. 
Según el parágrafo 23.3 de las NIIF para PYMES dicha medición de ingresos de actividades ordinarias se presenta de la siguiente forma:

Una entidad medirá los ingresos de actividades ordinarias al valor razonable de la contraprestación recibida o por recibir. El valor razonable de la contraprestación, recibida o por recibir, tiene en cuenta el importe de cualesquiera descuentos comerciales, descuentos por pronto pago y rebajas por volumen de ventas que sean practicados por la entidad (IASB, 2010).

Es así como, desde la operación inicial, se reconoce el hecho económico por el valor que cancelará el cliente neto de descuentos, así su pago fuere aplazado, lo que no ocurre con la denotación que hace la norma fiscal en el artículo 454 del ET. En efecto, esta norma se refiere a que solo los descuentos efectivos no formarán parte de la base para el cálculo del IVA, poniendo como requisito que los mismos consten en la factura o documento equivalente y así mismo no estén sujetos a condición alguna y sean normales dentro de la costumbre comercial, dejando de lado los descuentos financieros.

Una estrategia de uso frecuente por parte de las compañías son los incentivos que se otorgan a fin de obtener un pronto pago de la obligación. El numeral 8 del artículo 28 utiliza el término programas de fidelización y queda uno corto con el concepto, pero es el parágrafo 3 que da la definición de descuento o crédito. Además hay una limitación y es que condiciona su reconocimiento como ingresos a más tardar en el siguiente periodo fiscal pero, como ya se había anotado, sin hacer una referencia directa al impuesto a las ventas:

Los pasivos por ingresos diferidos producto de programas de fidelización de clientes deberán ser reconocidos como ingresos en materia tributaria, a más tardar, en el siguiente periodo fiscal o en la fecha de caducidad de la obligación si este es menor.

Parágrafo 3. Para efectos del numeral 8 del presente artículo, se entenderá por programas de fidelización de clientes aquellos en virtud de los cuales, como parte de una transacción de venta, un contribuyente concede una contraprestación condicionada y futura a favor del cliente, que puede tomar la forma de un descuento o un crédito (Ley 1819, 2016).

Algo muy similar sucede con el numeral 9, en el que se habla de ingresos provenientes de una contraprestación variable: aquella que se ve sometida a una condición, presentando como ejemplo el desempeño en ventas, cumplimiento de metas entre otros, y haciendo la indicación con referencia al Impuesto sobre la Renta y Complementarios.

La pregunta que quedaría es si los mismos no formarían parte de la base para el cálculo del IVA. Este último impactaría en la base gravable, dado que la norma internacional exige que el mismo sea reconocido desde el momento inicial teniendo en cuenta el comportamiento habitual con que los clientes toman dichos descuentos. Si esto último se viera desde otra óptica, las empresas podrían reconocer el descuento tanto comercial 
como financiero consultando la habitualidad de pagos de sus clientes desde el momento inicial por su valor neto, y si por alguna circunstancia su adquiriente no cumpliera con el plazo pactado podría formalizarse la factura bien sea por concepto de intereses o un ajuste de valor, respaldado esto último por el segundo inciso del artículo 448 del estatuto como un reajuste al valor convenido.

En el concepto 13716 de junio de 2017, la Dirección de Impuestos y Aduanas Nacionales (DIAN) emitió su punto de vista en el entendido de que la norma tributaria no establece limitaciones o excepciones al tratamiento contable de las NIIF para los descuentos por pronto pago, los cuales se registran como menor valor del ingreso en el caso de las ventas o como menor valor del inventario o del costo en el caso de las compras.

El consultante planteó la siguiente pregunta:

¿El nuevo tratamiento tributario que prescribe la sección 23.3 del anexo del Decreto 3022 del 2013 en el sentido de tratar los descuentos por pronto pago como un menor valor del ingreso y no como gasto financiero, es también aplicable para efectos tributarios, dado que no existe ley o decreto que indique lo contrario y que los decretos 2649 y 2650 de 1993 ya no son las normas contables aplicables en Colombia desde el $1^{\circ}$ de enero del 2016 ?

La DIAN en su respuesta refrendó la tesis de que los descuentos deberían considerar los criterios de reconocimiento y medición de las normas contables:

En la medida que la norma fiscal no contempló ninguna limitación o excepción sobre el tratamiento específico en los descuentos por pronto pago, se debe considerar los tratamientos de reconocimiento y medición, que establezcan las normas contables vigentes, para cada año gravable en este hecho económico, ya sea como menor valor del ingreso en el caso de las ventas o como menor valor del inventario o del costo en el caso de las compras.

No sobra advertir que cualquier ajuste que deba realizarse (en el ingreso, en el inventario o costo) entre el descuento tomado en el reconocimiento inicial de la transacción y el efectivamente realizado, deberá reconocerse igualmente para efectos fiscales en el período en el que se realice contablemente (Concepto 13716, 2017).

El concepto antedicho debe armonizarse con el Concepto 7077 emitido en marzo 29 de 2017, en el que a la DIAN se le plantearon sendos interrogantes acerca del adicionado artículo 21-1 del Estatuto Tributario:

1. Teniendo en cuenta dicha adición, ¿este sistema debe ser igualmente aplicable para el ingreso gravable en el impuesto sobre las ventas?

2. ¿Se debe declarar el IVA sobre el ingreso efectivamente facturado? 
Sobre el particular, este despacho se permite realizar las siguientes apreciaciones:

En efecto, el artículo 22 de la Ley 1819 del 2016 adicionó el artículo 21-1 al Estatuto Tributario. Sin embargo, es menester resaltar que los sistemas de reconocimiento y medición, señalados en dicho artículo son de aplicación exclusiva para la determinación del impuesto sobre la renta y complementarios, tal como lo indica la normativa en comento.

Así mismo, resulta conveniente mencionar que con la entrada en vigencia de la Ley 1819 del 2016 y para efectos del impuesto sobre la renta, el reconocimiento de los ingresos, costos y gastos para los obligados a llevar contabilidad se encuentra incorporado con el nuevo concepto del "devengo o acumulación” en los nuevos marcos técnicos contables. Término, que describe principalmente los efectos de las transacciones y otros sucesos y circunstancias sobre los recursos económicos.

En virtud de lo anterior y frente al primer interrogante, es dable inferir que dicho sistema de reconocimiento y medición de conformidad con los nuevos marcos técnicos normativos contables vigentes en Colombia es aplicable solo para la determinación del Impuesto de renta y Complementarios para aquellos sujetos pasivos del mismo, obligados a llevar contabilidad.

Respecto al segundo interrogante, le informamos que el responsable del impuesto sobre las ventas tiene la obligación legal de recaudar, declarar, y consignar el impuesto sobre aquellos hechos económicos en los que se cause de conformidad con el artículo 429 del estatuto tributario. Por tal razón, el valor -ingreso- que se debe registrar en la declaración del impuesto sobre las ventas, del período correspondiente de acuerdo al artículo 600 del Estatuto Tributario, no es otro que el efectivamente facturado con el lleno de los requisitos señalados en el artículo 617 del mismo estatuto.

A pesar de la obligatoriedad de dichos conceptos emitidos por la DIAN para sus propios funcionarios, que determinarán las actuaciones a realizar por parte de los contribuyentes al presentar tributos ante el fisco, ello no es óbice para que se efectúen los análisis pertinentes en torno a los postulados expuestos por la autoridad fiscal, dado que no se comparten.

En primer lugar, los conceptos plasmados por la DIAN efectúan una interpretación restrictiva de la norma tributaria, dado que estatuyen que las NIIF solo resultan aplicables en lo que corresponde al impuesto de renta y no así frente al IVA, dejando presente la existencia de una multiplicidad normativa contable e imposibilitando una adecuada implementación y consolidación de las Normas Internacionales de Información Financiera en el ámbito colombiano.

En segundo lugar, puede evidenciarse que los análisis llevados a cabo por la DIAN en estos conceptos no se ocupan de un estudio normativo profundo ni de interpretaciones sistemáticas de las normas, sino de interpretaciones apenas literales de la mismas, lo que los lleva a concluir, sin lugar a dudas, que las NIIF, en cuanto a estos conceptos, solo se aplican al impuesto de renta y no al impuesto al valor agregado, pese a las implicaciones prácticas que tales concepciones implican. 
No deja de sorprender, en dicho aspecto, que se presenten dos conceptos de la DIAN con casi un año de diferencia y, sin embargo, la posición de la entidad se mantenga idéntica y no se efectúen mayores planteamientos sobre el tema, a pesar de tratarse de asuntos de altísima actualidad en los que el contribuyente espera determinaciones rigurosas y sustentadas de la Administración, máxime cuando la totalidad de funcionarios públicos adscritos a dicha entidad fiscal deberán aplicar las disposiciones de los mismos, de cara al carácter de fuente obligatoria que ostentan estos en materia tributaria, de conformidad con lo expuesto por la normativa vigente.

Así, la referencia doctrinaria que en dichos conceptos la DIAN refiere a sus mismos funcionarios, carece de profundidad argumentativa y de elementos adicionales que le permitan al servidor la comprensión de las razones de la entidad para la aplicación de los postulados normativos en ese sentido y no en otro, máxime cuando los conceptos están circunscritos a casos muy concretos.

Finalmente, debe rememorarse que las determinaciones de la autoridad fiscal en lo que corresponde a la no aplicación de las NIIF en IVA da lugar a que las compañías trancen los descuentos condicionados desde la realización inicial del hecho económico y con ello da un salvoconducto para que este tipo de transacciones sean permitidas, situación que sin lugar a dudas afectará la practicidad de las transacciones y, en últimas, el recaudo fiscal pretendido.

Justamente, son estas determinaciones prácticas las que resultan concluyentes en los problemas jurídicos planteados en el presente trabajo, dado que es el contribuyente el que sentirá las repercusiones profundas que la no aplicación de las NIIF le generan. De allí que resulte determinante en el presente escrito esbozar cómo toda esta discusión teórica, que parece de poca monta, tiene una repercusión real profundamente interesante.

Para entender de mejor manera lo expuesto, se plantea el siguiente ejercicio con sendos escenarios, uno con el reconocimiento inicial de una venta con dos tipos de descuento, uno comercial o llamado pie de factura y un descuento financiero llamado igualmente descuento condicionado. En el mismo se evidenciarán las divergencias monetarias que se presentarán en la realidad -en la determinación del tributo y la tarifa a pagar- según se apliquen los conceptos de la norma fiscal o de las NIIF, asunto cumbre del escrito planteado:

TABLA 6. EJEMPLO de VENTA CON DESCUENTO COMERCIAL Y FINANCIERO

\begin{tabular}{|l|r|r|}
\hline & Tratamiento NIIF & Tratamiento fiscal \\
\hline $\begin{array}{l}\text { Valor antes de IVA } \\
\text { Valor de mercado }\end{array}$ & 2.000 .000 & 2.000 .000 \\
\hline Descuento Comercial 5\% & $(100.000)$ & $(100.000)$ \\
\hline $\begin{array}{l}\text { Descuento financiero 10\% } \\
\text { Pago antes de 60 días }\end{array}$ & $(200.000)$ & \\
\hline Base & 1.700 .000 & 1.900 .000 \\
\hline IVA 19\% & 323.000 & 361.000 \\
\hline
\end{tabular}

Fuente: Elaboración propia. 
De acuerdo con la norma internacional, el valor razonable de esta operación es de $\$ 1.700 .000$, pues es el valor por el cual la compañía vendedora estaría dispuesta a vender el bien y su cliente, la compañía adquiriente, estaría dispuesta a pagar por su obtención.

Ahora supongamos que el comprador incumplió el pago dentro del término acordado y solo lo realizó en el día 90 , entonces se debería facturar los $\$ 200.000$ por concepto de intereses, o como reajuste al valor convenido.

$\begin{array}{lr}\text { Caja-Bancos-Clientes } & 238.000 \\ \text { Ingresos de actividades ordinarias } & 200.000 \\ \text { IVA por pagar } & 38.000\end{array}$

Para hacer hincapié en lo que intenta retratarse, se presenta un caso real, en el que se puede evidenciar la trascendencia de la discusión que se efectúa y en la que se determinará, en igual medida, cómo el empleo de la norma fiscal o de las NIIF afecta la base gravable para el IVA.

En el caso que nos ocupa, presento a una compañía que distribuye medicamentos. Para el año 2016 sus ventas ascendieron a la suma de \$21.000 millones de los cuales $\$ 6.000$ millones correspondían a descuentos comerciales condicionados. Desde que fue constituida la referida empresa, sus proveedores otorgan un descuento condicionado del $20 \%$ si su pago se hiciese antes de 90 días, condición que nunca se incumplió dada la importancia que tenían dichos descuentos en los resultados netos operacionales. De hecho, analizando sus estados de resultados, la compañía por lo general arrojaba pérdida operativa, es decir, los resultados luego de detraer los gastos administrativos y de ventas; pero luego de presentar como ingresos no operacionales los descuentos comerciales, se revierte el resultado, ya arrojando un resultado positivo antes de la provisión del impuesto de renta. Dada la importancia de los descuentos y la suma que ellos representan como base de liquidación del IVA, para el año 2017, decidieron que dicho descuento quedase concertado desde el momento en que se expide la correspondiente factura de venta, lo cual haría significativo el no volver dichos descuentos base gravable en el IVA.

El beneficio de aplicar NIIF en el presente caso, hizo que la compañía develara su verdadera situación de negocios, la cual no era obtener utilidad operativa a través de descuentos sino adquirir sus productos a un valor razonable o de mercado con un margen de rentabilidad que desde el inicio de la operación se tenía presupuestado y que permitiera al final del ejercicio obtener beneficios por encima de su punto de equilibrio y que sus accionistas obtuvieran la rentabilidad esperada de su inversión.

Es por lo anterior que el verdadero sentido de aplicar la Norma Internacional fuera que las compañías presentaran su información financiera de manera clara sin recurrir a artificios que lo que hacían era presentar una información alejada de su realidad. 


\section{J. Pago diferido}

En la Norma Internacional se analizó que una operación con plazos que superaran los normalmente acostumbrados y que sean refrendados por política contable al interior de cada compañía, se deberían reconocer desde el comienzo de la transacción al valor presente de acuerdo con la tasa de mercado para instrumentos financieros de similar condición.

El modificado artículo 28 del Estatuto Tributario, en su parágrafo 2, lo reguló de esta manera, haciendo una refrendación de la norma internacional:

Entiéndase por interés implícito el que se origina en aquellas transacciones de financiación, que tienen lugar cuando los pagos se extienden más allá de los términos de la política comercial y contable de la empresa, o se financia a una tasa que no es una tasa de mercado.

La NIIF 9, que es la par de la sección 23 de las NIIF para PYMES, tiene un desarrollo conceptual muy similar en cuanto a la medición de los ingresos de actividades ordinarias, definiéndolo en el párrafo 9 de la siguiente manera: "Los ingresos de actividades ordinarias se medirán al valor razonable de la contraprestación recibida o por recibir”.

A través de un ejemplo se presentará lo concerniente a los ingresos cuyo pago se ve sometido a un diferimiento en el tiempo y que se debe reconocer por el valor presente de una tasa de interés de mercado. Esta forma de reconocer los ingresos utilizando el concepto de valor presente pretende separar el valor nominal de la venta de contado del valor de los intereses explícitos o implícitos. El valor del dinero en el tiempo tiene un impacto cuando una venta que pudiere efectuarse de contado se realiza a crédito, a unos plazos que excedan los usualmente convenidos. En efecto no es lo mismo vender un bien a un precio $\mathbf{X}$ el día de hoy y hacer efectivo el recaudo el mismo día, a recibir esa misma suma al cabo de los 6 meses. O de otra manera, financiar dicha venta a una tasa de interés muy inferior a la tasa de mercado de un instrumento similar. Este es el costo de oportunidad de colocar el dinero en actividades que renten más de lo que paga el mercado.

Si bien el IVA nominalmente sería el mismo, su cálculo se realizaría a medida que los intereses se causen durante la vida del crédito. Así lo estipula el parágrafo 23.5 de las NIIF para PYMES:

Cuando se difieren las entradas de efectivo o equivalentes al efectivo y el acuerdo constituye efectivamente una transacción financiera, el valor razonable de la contraprestación es el valor presente de todos los cobros futuros determinados utilizando una tasa de interés imputada. Una transacción financiera surge cuando, por ejemplo, una entidad concede un crédito sin intereses al comprador o acepta un efecto comercial, cargando al comprador una tasa de interés menor que la del mercado, como contraprestación por la venta de bienes. La tasa de interés imputada será, de entre las dos siguientes, la que mejor se pueda determinar: 
a) la tasa vigente para un instrumento similar de un emisor con una calificación crediticia similar, o

b) la tasa de interés que iguala el importe nominal del instrumento con el precio de venta en efectivo actual de los bienes o servicios.

Una entidad reconocerá la diferencia entre el valor presente de todos los cobros futuros y el importe nominal de la contraprestación como ingreso de actividades ordinarias por intereses, de acuerdo con los párrafos 23.28 y 23.29 y con la Sección 11 (IASB, 2010).

Lo que trata la NIIF en esta materia son las ventas de bienes o prestación de servicios que ya fueron cristalizadas pero el pago tuvo un diferimiento más allá de los plazos que usualmente se otorgan.

A continuación se presentará un ejemplo en el que claramente se pueden retratar las diferencias que se edifican en torno a los pagos diferidos, cuando se produce aplicación de las NIIF frente al empleo de la norma fiscal:

La empresa XYZ efectúa una venta de mercancías al señor Pérez con un plazo de dos años por valor de $\$ 2.000 .000$. La tasa de interés de mercado es del 10\% anual para un instrumento similar. Haré los registros correspondientes del IVA en el reconocimiento Inicial y el diferimiento de dicho pago aplazado.

Aquí se puede efectuar un cálculo del interés de financiación de dos maneras:

a) Uno podría ser de fácil consulta por cuanto se conocen la tasa de interés que está dispuesta a conceder el mercado por instrumento similar, en este caso la tasa de financiación de facturas, como podría ser el factoring o compra de cartera.

b) La otra forma es hallar la tasa de interés implícita de financiamiento, llamada también la TIR (Tasa Interna de Retorno), que es aquella tasa que se encarga de distribuir los ingresos por intereses (que es nuestro caso) o los gastos por intereses en el periodo de tiempo que dura la financiación.

TABLA 7. Venta CON PLAZO DIFERIDO

\begin{tabular}{|l|r|r|r|}
\hline \multicolumn{5}{|c|}{ Venta a crédito a 2 años } \\
\hline & Método de valor presente & \multicolumn{1}{c|}{ Periodos } & \multicolumn{1}{c|}{ Método de TIR } \\
\hline Valor con financiación & 2.000 .000 & 0 & $(1.652 .893)$ \\
\hline Periodos & 2 & 1 & 0 \\
\hline Tasa $10 \%$ & $(200.000)$ & 2 & 2.000 .000 \\
\hline Valor presente & 1.652 .893 & TIR & $10 \%$ \\
\hline Intereses & 347.107 & & \\
\hline
\end{tabular}

Fuente: Elaboración propia.

El anterior planteamiento tiene 2 supuestos que llevan al mismo resultado. 
El primero parte de que se conoce la tasa de mercado, que en este caso es del $10 \%$ y tiene un valor de $\$ 2.000 .000$ que se financiará a dos años. Se necesita hallar el valor equivalente de los \$2.000.000 si se recaudaran en el periodo en el que se pactó la venta. Para este caso debere recurrir a la fórmula de valor presente, que es:

$$
\mathrm{VP}=-\frac{\mathrm{VF}}{(1+i)^{n}}
$$

Donde:

$\mathrm{VF}=\$ 2.000 .000$

$\mathrm{i}=10 \%$ (Tasa de interes de mercado)

n= 2 (Número de peridos en este caso corresponde a 2 años)

El segundo supuesto se conoce el valor actual (de contado) del bien a vender ( $\$ 1.652 .893$ ) y también se sabe cuál es el valor que debería cobrar a futuro incluida la financiación (\$2.000.000). Como se necesita reconocer cuánto le corresponde de financiación a cada uno de los periodos, se requiere hallar la tasa que hace equivalente dicho valor. Para ello debe recurrirse a la fórmula financiera de la Tasa interna de Retorno, TIR.

Teniendo la tasa y el valor valor presente se procede a multiplicar el saldo inicial de cada periodo por la tasa de interes, la cual se va capitalizando hasta llegar al resultado final.

Tabla 8. Tabla de costo amortizado

\begin{tabular}{|l|r|r|r|}
\hline \multicolumn{3}{|c|}{ Método de costo amortizado } \\
\hline Fecha & Fórmula & Gasto financiero & \multicolumn{1}{c|}{ Costo amortizado } \\
\hline Año 0 & & & $1.652 .893,00$ \\
\hline Año 1 & $\$ 1.652 .893,00 \times 10 \%$ & $165.289,26$ & $1.818 .181,82$ \\
\hline Año 2 & $\$ 1.818 .181,82 \times 10 \%$ & $181.818,18$ & $2.000 .000,00$ \\
\hline & & $347.107,44$ & \\
\hline
\end{tabular}

Fuente: Elaboración propia.

Como el valor inicial es el valor razonable del bien en el momento de su negociación, lo que se cobra adicional a dicho valor corresponde a financiación.

\section{Tabla 9. Cálculo del iva sobre el Valor diferido}

\begin{tabular}{|r|r|r|r|r|}
\hline \multicolumn{5}{|c|}{ Cálculo del IVA } \\
\hline Fecha & Fiscal & \multicolumn{1}{|c|}{ IVA } & \multicolumn{1}{c|}{ NIIF } & \multicolumn{1}{c|}{ IVA } \\
\hline Año 0 & $\$ 2.000 .000$ & $\$ 380.000$ & $\$ 1.652 .893$ & $\$ 314.050$ \\
\hline Año 1 & & & $\$ 165.289$ & $\$ 31.405$ \\
\hline Año 2 & & & $\$ 181.818$ & $\$ 34.545$ \\
\hline & $\$ 2.000 .000$ & $\$ 380.000$ & $\$ 2.000 .000$ & $\$ 380.000$ \\
\hline
\end{tabular}

Fuente: Elaboración propia. 
Su contabilización sería:

Año 0

Clientes

1.966 .942

Ingresos de actividades ordinarias

1.652 .893

(Venta de bienes)

IVA por pagar

Año 1

Clientes

Ingresos de actividades ordinarias

Intereses

IVA por pagar

Año 2

Clientes

Ingresos de actividades ordinarias

Intereses

IVA por pagar
216.363

181.818

34.545

Del anterior ejercicio se puede notar cómo el reconocimiento del IVA se hace de manera diferida partiendo de una medición inicial a valor presente, es decir, podría presentarse un diferimiento en el pago del IVA y esta diferencia tomar visos de legalidad por lo conceptuado en el parágrafo del artículo 429 del ET como un aumento de valor con posterioridad a la venta. "Parágrafo. Cuando el valor convenido sufriere un aumento con posterioridad a la venta, se generará el impuesto sobre ese mayor valor en la fecha en que este se cause".

El ejemplo precitado pone presente que en pagos diferidos aplicando la norma internacional, la DIAN no tendrá manera de recaudar de manera inmediata el IVA, pues la misma solo se materializará con cada una de las facturas emitidas por dichos pagos diferidos.

Efectuar esta clase de mediciones bajo NIFF les posibilitaría a las empresas efectuar el recaudo del IVA en la medida en que se materialicen cada uno de los pagos realizados por sus clientes, lo que permitiría tener un mejor flujo de caja a los responsables de dicho impuesto sin que ello signifique un detrimento para el estado por menor recaudo de IVA. Diferente de lo que ocurre en la actualidad con la causación del IVA, donde el total del impuesto se recauda sin el menor compadecimiento con el empresario, quien es el que debe asumir de su propio pecunio su financiación. 


\section{K. Transferencia de riesgos y beneficios}

Otra de las novedades de la Norma Internacional es el reconocimiento de los ingresos en la transferencia de riesgos y beneficios. Aunque si bien el artículo 429 del ET en su literal a ya lo había definido como uno de los momentos en que el impuesto se causaba, es un tema al que no le han prestado la debida atención, pues se acostumbró a que hasta tanto no existiera el documento físico no se causaba el IVA.

a) En las ventas, en la fecha de emisión de la factura o documento equivalente y a falta de estos, en el momento de la entrega, aunque se haya pactado reserva de dominio, pacto de retroventa o condición resolutoria.

Lo anterior para bien del recaudo de IVA, pues ello contribuiría de manera positiva a su cobro anticipado, y es el hecho que los ingresos se deben reconocer independientemente de la forma que se le dé al contrato, pues lo importante es la esencia de la transacción.

El parágrafo 23.10 de las NIIF para PYMES trae consigo unos condicionantes que se deben cumplir a cabalidad para el reconocimiento de los ingresos:

a) Que la entidad haya transferido al comprador los riesgos y ventajas inherentes a la propiedad de los bienes.

b) Que la entidad no conserve ninguna participación en la gestión de forma continua en el grado usualmente asociado con la propiedad, ni retenga el control efectivo sobre los bienes vendidos.

c) Que el importe de los ingresos de actividades ordinarias pueda medirse con fiabilidad.

d) Que sea probable que la entidad obtenga los beneficios económicos asociados de la transacción.

e) Que los costos incurridos, o por incurrir, en relación con la transacción puedan ser medidos con fiabilidad.

Llama la atención el literal a del parágrafo 23.10 y el parágrafo 23.11, pues ejercen un impacto relevante en aquellas entidades que tienen como regla reconocer un ingreso solo cuando se expide la factura de venta, que es muy común en las ventas al por menor donde la titularidad legal coincide con la entrega material de las mercancías, pero en otros casos no siempre dicha trasferencia de riesgos y beneficios coincide con la titularidad; principio de la esencia económica sobre la forma legal.

La Norma Internacional plantea el reconocimiento de ingresos cuando se haya realizado la transferencia de riesgos y beneficios, independientemente de que no exista la factura o documento que respalde la operación. El parágrafo 1 del artículo 28 del Ет hace una anotación en el sentido de que si contablemente no se cumplen criterios de reconocimiento como ingresos, porque por ejemplo no hay transferencia de riesgos y beneficios, pero le 
asiste al vendedor el derecho a cobro por mediar un contrato que lo obligue; esta operación debe reconocerse para efectos fiscales como un ingreso.

Esta disposición va en completa contraposición con la norma internacional y consecuentemente con la realidad financiera, pues entretanto no se tenga una certeza razonable de que existe la venta no tiene sentido tener que cancelar de manera anticipada el IvA por una operación sobre la cual no existe certidumbre de que se lleve a cabo. Este tipo de normas lo que hace es desincentivar el comercio de bienes cuando sean solicitados a crédito que es en la mayoría de ocasiones como son transadas.

\section{Conclusiones}

El objetivo se centró en determinar cuáles eran las incidencias en la causación del IVA en Colombia bajo las Normas Internacionales de Información Financiera en cuanto al reconocimiento y medición de los ingresos operacionales. Así mismo se llevó a cabo una breve descripción del valor razonable de la NIIF 13, el cual contiene los elementos conceptuales y metodológicos para definir el término valor comercial que contiene el Estatuto Tributario. Esta metodología conduce a que exista una forma de resolver la indeterminación del término valor comercial y su real utilidad en las diferentes disposiciones que se inserta en el estatuto fiscal colombiano.

Como punto de partida, se aludió a la incorporación que hiciera la Ley 1819 de 2016 en el ordenamiento tributario de la nueva normatividad contable, pero al disponer de forma expresa su aplicación en el impuesto sobre la renta, dejó al régimen de impuesto sobre las ventas, por fuera de su ámbito. La anterior afirmación es concluyente al tenor del artículo 4 de la Ley 1314 de 2009 en el que si bien se expresó la independencia de las normas tributarias sobre las contables, estas últimas tendrían incidencia cuando las leyes tributarias remitieran expresamente a ellas o no regularan los efectos impositivos. De ahí que supondría que en cuanto al reconocimiento y medición de la base gravable del IVA se supeditará a la norma contable internacional basada en la regla de supletoriedad, donde la norma financiera entre a llenar los vacíos normativos.

Partiendo de dicho supuesto es que se planteó la forma de determinar el impuesto a las ventas en:

\section{- Medición de los ingresos con descuentos financieros}

En cuanto a este punto, ya la DIAN emitió su punto de vista con el Concepto 13716 de junio 1 de 2017, en el cual manifestó que los descuentos como la ley no contempló limitaciones, daba por sentado que el reconocimiento de ingresos se debía realizar a lo referido por la técnica contable, no aceptándolo así en el Concepto 7077 de marzo de 2017, que reseña que los sistemas de reconocimiento y medición solo son aplicables al impuesto sobre la Renta. Así mismo lo ratificó en el Concepto 0035 del 5 de enero de 2018 donde pone de presente lo dicho en el Concepto 13716 subrayando que solo los efectos de los descuentos son para el impuesto de renta mas no para IVA, lo que en últimas generaría un 
problema técnico que dificultaría la conciliación fiscal, pues habría una información de ingresos para renta y otra información de ingresos para IVA.

Los descuentos condicionados o comerciales han tenido como finalidad ser una fuerte motivación para que los pagos se hagan en un periodo de tiempo acordado, y cuya concepción está dada para que aun en el caso en que este sea otorgado, los márgenes de rentabilidad del concedente estén dentro de los presupuestos de su utilidad mínima operacional, es decir que nadie da descuentos por debajo del costo de la mercancía a transar. Lo anterior bajo la Norma Internacional es un indicador de que el verdadero valor razonable es el ingreso neto de descuentos, por lo que es de allí que su reconocimiento se deba realizar desde un comienzo por ese valor neto.

De allí surge la teoría de que la base gravable tanto para renta como para IVA deba reconocerse por su valor de mercado. En este punto la legislación fiscal española está más alineada con las disposiciones financieras internacionales al reconocer que los descuentos admitan estas aminoraciones para el cálculo de IVA (Royo, 2016).

\section{- Pago diferido}

Este punto demandará estudiarse de manera muy prudente por parte no solo de abogados, contadores y los distintos profesionales dedicados a la consultoría tributaria, sino a los funcionarios de la DIAN, en entender cómo es el manejo financiero cuando hay una venta con pagos aplazados y conocer que ya no hay una regla que establezca de manera única esta técnica financiera, sino que dependerá de la política contable que aborde cada compañía; ello conllevará que sean múltiples las variables tanto en periodos de vencimiento como en tasas de interés efectiva sobre los que se harán los cálculos financieros, para determinar el valor presente de cualquier operación de venta.

Si bien el costo histórico sigue siendo de manera preferente la forma en que se miden los hechos económicos, el valor razonable viene mostrando ser una medida de gran aceptación en las diferentes jurisdicciones que han incorporado las normas internacionales y más cuando la medición a valor de mercado se dispone en gran parte del articulado del Estatuto Tributario.

En mi opinión, el modelo NIIF busca alinear la contabilidad con los propósitos recaudatorios del Estado y es así como en los pagos diferidos, el IVA debería corresponder a una medida justa y proporcional al valor anticipado, ya que de esta manera las compañías podrían garantizar que los flujos de efectivo producto de la venta se repartan de manera equitativa entre el empresario y el Estado, ya que como el IVA se paga de manera anticipada, los responsables reciben un $19 \%$ menos del total de la venta sujeta a financiación.

La Norma Internacional entiende que cuando una operación se somete a un plazo superior al que usualmente está concertado en la política contable, es porque la entidad ha presupuestado esta financiación en el precio final del bien. Esta separación entre el valor final y el valor inicial o de mercado es lo que se concibe como intereses, los cuales son base gravable del IVA, según está dispuesto en el artículo 447 del ET. Es por lo anterior 
que el IVA se debería liquidar en la medida en que la financiación se vaya devengando a través del tiempo y no que el impuesto se cause desde el momento inicial de la operación. Teniendo el IVA una representatividad del 19\% sobre el valor de la operación inicial, se estaría liquidando por un valor sobre el que no existe recaudo y que no es un secreto para nadie que ello causa un problema de flujo de caja en las empresas que utilizan esta estrategia de negocio.

\section{- Transferencia de riesgos y beneficios}

Hay una evolución a nivel mundial de administración de servicios y gestión de riesgos. La primera se denomina economía experiencial y de servicios y en donde los acuerdos de nivel de servicios deben ser tan amplios que permitan negociaciones internacionales donde los intercambios sean libres sin restricciones financieras. En cuanto a la gestión de riesgos, las empresas tendrían que generar documentos de garantía que permitan medir hasta dónde estas asumen riesgos y hasta dónde los clientes, pues de ello dependería el valor transaccional. Este asunto va a generar discusiones con la Administración, puesto que será difícil saber el momento en el cual se causará el IVA. Ya vimos que la Norma Internacional plantea ciertas condiciones que a mi modo de ver tiene un grado de subjetividad demasiado alto, el cual deberá estar documentado con la política contable.

Una de estas condiciones es la transferencia de riesgos y beneficios, y bajo esta circunstancia poco o nada importa la titularidad legal de quien se obliga en la operación de venta. El parágrafo 23.11 plantea que tal situación requiere un examen de las circunstancias de la transacción, es decir, deja a los sujetos involucrados en la transacción el examen de dicha transferencia. En el parágrafo 23.12 se plantea el no reconocimiento en las situaciones siguientes:

- La entidad conserva una obligación por funcionamiento insatisfactorio; este hecho está dado por garantías de los bienes y servicios que se comercializan y la venta está condicionada a la satisfacción por parte del comprador.

- Los ingresos están condicionados a la venta por parte del comprador, circunstancias muy comunes cuando se dejan mercancías en consignación y a medida que estas se venden se genera la obligación del comprador con el vendedor.

- Cuando los bienes están supeditados a instalación y esta es una parte significativa del contrato. Muy frecuente en transacciones bienes y servicios que demandan alta tecnología.

- Cuando el adquiriente tiene el derecho a rescindir la compra por cuestiones contractuales. En Colombia el artículo 47 de la Ley 1480 de 2011 del Estatuto del Consumidor otorga un término de 5 días hábiles para ejercer el derecho de retracto. En estas circunstancias ninguna venta se debería reconocer hasta tanto no se cumpla el señalado término. Pero también se puede concertar un término superior por acuerdo entre las partes, lo que implicaría reconocer los ingresos por encima de este plazo. 


\section{- Determinación del Valor comercial}

El Estatuto Tributario trae en un número importante de su articulado el término valor comercial, pero no ha tenido un desarrollo normativo adecuado y no existe en la doctrina ni en la jurisprudencia una fórmula técnica de cómo desarrollarlo; tanto el Código de Comercio como en la norma internacional confluyen algunos elementos comunes, como son:

- Compradores y vendedores.

- Fecha y lugar de la operación.

- Precio.

- Mercado (zona geográfica).

- Bienes.

Es por ello que la Norma Internacional propone una solución a este impase cuando en la NIIF 13 plantea un sinnúmero de técnicas para la determinación del valor de mercado, y es allí donde el valor razonable cobra una gran importancia gracias a que llena el vacío que trae el Estatuto Tributario en este tema.

- La medición a valor razonable tiene el sustento normativo para ser base gravable del IVA

El artículo 4 de la Ley 1314 de 2009 consagró 2 tipos de remisiones hacia las normas contables. Una expresa cuando refirió que "Las normas expedidas en desarrollo de esta ley, únicamente tendrán efecto impositivo cuando las leyes tributarias remitan expresamente a ellas..." y una regla por omisión "o cuando estas no regulen la materia". Si bien el precitado artículo fue sometido a examen de constitucionalidad por medio de la Sentencia C-1018 de noviembre de 2012, el alto tribunal en su examen hizo referenciaría a la reserva de ley y se circunscribió a la expresión “efecto impositivo". Además señaló que las normas de contabilidad e información financiera expedidas por el presidente en desarrollo de esta ley tendrían efectos impositivos cuando las normas fiscales remitieran expresamente a ellas o cuando estas no regularan de manera expresa la materia. Para la Corte, lo que existe es una subsidiaridad de los reglamentos de información financiera, y su aporte es servir de elemento administrativo, para que cuando haya carencia de dichos reglamentos, pueda la Administración hacer uso de ellos. Si bien es cierto, como lo entendió la Corte, que las normas contables no introducían nuevos elementos que establecieran nuevos tributos vulnerando los artículos 150 y 338 de la Constitución Política, las normas contables sí tienen la particularidad de modificar las bases gravables como lo hemos visto con la aminoración que producen los descuentos financieros, de manera transitoria cuando se utiliza el método de valor presente y que difiere la causación del IVA, así como lo hace cuando se registran los hechos económicos con el concepto de asunción de riesgos y beneficios. Muy seguramente muchas compañías harán uso de estas herramientas que ofrecen las normas financieras y será la Administración la que tendrá que recaracterizar o reconfigurar dichas operaciones cuando las mismas sean usadas de manera abusiva. 


\section{Referencias}

Arias Bello, Martha Liliana y Salazar Baquero, Édgar Emilio (2012). Efectos del debido proceso en la formulación de la NIIF 13: Mediciones a Valor Razonable. Bogotá: Universidad Javeriana. Mayo 6 de 2012.

Bonnot de Condillac, E. (julio-diciembre de 2012). Cuadernos de contabilidad. / vol. 13 / no. 33 / julio-diciembre 2012 pág. 14. 13(33).

Concepto 13716 (1 de junio de 2017). DIAN. Obtenido de http://www.globbal.co/wp-content/uploads/2017/07/28-Con-DIAN-13716-2017-Descuentos-por-pronto-pago. pdf

Corte Constitucional. Sentencia C-1018 de noviembre 28 de 2012.

Decreto 2420 de 2.015. Diario Oficial $\mathrm{n}^{\circ} .49 .726$ de 14 de diciembre de 2015 .

Decreto 2548 de 2014. Diario Oficial 49363 de diciembre 12 de 2014.

Decreto reglamentario 3022 de 2013. Diario Oficial $n^{\circ} .49 .016$ de 27 de diciembre de 2013.

DIAN (2019). Concepto unificado de IVA. Codex. . Obtenido de www.dian.gov.co

Estatuto Tributario Colombiano (Decreto 624 de 1989). Diario Oficial 38756 de Marzo 30 de 1989

Hutchinson, M. G. ( julio-diciembre de 2012). Cuadernos de contabilidad. 13(33).

IASB (2009). NIIF PARa PYMES.

IASB (2010). NIIF para PYMES.

Law, J. (julio-diciembre de 2012). Cuadernos de contabilidad. 13(33).

Ley 1314 de 2.009 y sus anexos técnicos. Diario Oficial 47.409 de julio 13 de 2009.

Ley 1819 (Congreso de la república 29 de diciembre de 2016).

Manual práctico impuesto al valor añadido. (2017). Agencia tributaria. Ministerio de Hacienda y Función Pública. 
Meza Orozco, Johnny de Jesús (2015). Valoración de instrumentos financieros en NIIF para Pymes. Bogotá: Ediciones de la U.

Molina, L. (julio-diciembre de 2012). Cuadernos de contabilidad. 13(33).

Pérez Royo, Fernando (2016). Curso de Derecho tributario parte especial. (10ª ed.) Madrid: Editoriales Tecnos.

Petty, W. (julio-diciembre de 2012). Cuadernos de contabilidad. 13(33).

Piza, Julio Roberto (2015). Análisis del Hecho Generador del IVA en el ordenamiento Jurídico Colombia. Bogotá: Universidad Externado de Colombia..

Piza, Julio Roberto (2017). Analisis del hecho generador del IVA en el ordenamiento jurídico colombiano. Bogotá: Universidad Externado de Colombia.

Plazas Vega, Mauricio (2015). El Impuesto Sobre el Valor Agregado (3ª ed.) Bogotá, Colombia. Editorial Temis.

Queralt, Juan Martín (2016). Manual de Derecho tributario parte especial. (11 a ed.) Pamplona, España. Thomson Reuters.

Royo, P. F. (2016). Curso de Derecho Tributario. Madrid: Editorial Tecnos.

Sánchez Serna, Aracely del Socorro y Arias Bello, Martha Liliana (2012). Concepción de valor y precio desde Aristóteles a los clásicos: una reflexión a la luz de las premisas de valoración de las Normas Internacionales de Información Financiera, NIIF* Cuadernos de contabilidad. / Bogotá, colombia, 13 (33): 433-462 / julio-diciembre 2012.

Sewall (julio-diciembre de 1971). Cuadernos de contabilidad 13(33).

Smith, A. (julio-diciembre de 2012). Cuadernos de contabilidad / vol. 13 / no. 33 / julio-diciembre 2012 pág. 18. 13(33).

Vega, P. (2015). Impuesto al Valor Agregado. Bogotá:. Editorial temis. 